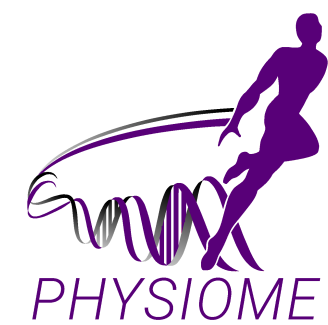

Published 24 Sept. 2020

\title{
Computational Modeling of Coupled Energetics and Mechanics in the Rat Ventricular Myocardium
}

\author{
Bahador Marzban ${ }^{1}$, Rachel Lopez ${ }^{1}$, and Daniel A. Beard ${ }^{1 *}$ \\ ${ }^{1}$ Molecular and Integrative Physiology, University of Michigan, Ann Arbor, Michigan, USA
}

\section{ORIG INAL}

\begin{abstract}
This paper details a multi-scale model computational model of myocardial energetics-oxidative ATP synthesis, ATP hydrolysis, and phosphate metabolite kinetics-and myocardial mechanics used to analyze data from a rat model of cardiac decompensation and failure. Combined, these two models simulate cardiac mechano-energetics: the coupling between metabolic production of ATP and hydrolysis of ATP to generate mechanical work. The model is used to predict how differences in energetic metabolic state found in failing versus control hearts causally contribute to systolic mechanical dysfunction in heart failure. This Physiome paper describes how to access, run, and manipulate these computer models, how to parameterize the models to match data, and how to compare model predictions to data.
\end{abstract}

Keywords: cardiac energetics, cardiac mechanics, heart failure, mechano-energetic coupling, multi-scale modeling

\section{Curated Model Implementation}

http: //doi.org/10.36903/physiome. 12964970

\section{Primary Publications}

R. Lopez, B. Marzban, X. Gao, E. Lauinger, F. Van den Bergh, S. E. Whitesall, K. Converso-Baran, C. F. Burant, D. E. Michele, and D. A. Beard. Impaired Myocardial Energetics Causes Mechanical Dysfunction in Decompensated Failing Hearts. Function, 09 2020. ISSN 2633-8823. doi: 10.1093/function/zqaa018. URL https://doi .org/10.1093/function/zqaa018.

OPEN ACCESS Reproducible Model

Edited by David P. Nickerson

Curated by

Anand K. Rampadarath

*Corresponding author beardda@umich.edu

Submitted 15 Sept. 2020

Accepted 15 Sept. 2020

Citation

Marzban et al. (2020) Computational Modeling of Coupled Energetics and Mechanics in the Rat Ventricular Myocardium. Physiome. doi: $10.36903 /$ physiome.12964970

\section{Introduction}

The multi-scale modeling approach is summarized in Fig. 1. Model components representing myocardial metabolism Bazil et al. (2016), myocardial cell mechanics Tewari et al. (2016a,b), myocardial whole-organ pumping Lumens et al. (2009), and a simple lumped circulatory model are integrated together to simulate whole-body cardiovascular function.

All computer codes are available at https://github.com/beards-lab/Rat-Cardiac-Energetic.

- The cardiac metabolic energetic model component is parameterized to match data from individual animals based on the oxidative capacity and cytoplasmic metabolite pools obtained from Lopez et al. (2020).

- Certain parameters from the cross-bridge and calcium-activation models of Tewari et al. (2016a,b) and Campbell et al. (2018) are re-estimated to match data from Janssen et al. (2002) on calcium transients and force-generation in isolated rat cardiac trabeculae, as detailed below. 
- Wall volumes and anatomic parameters associated with the Lumens et al. (2009) heart model are identified based on anatomical data obtained from echocardiography and ex-vivo gross morphological measurements on individual animals from Lopez et al. (2020).

- The simple lumped parameter circulatory model is identified based on cardiovascular state variables measured under resting conditions.

The resulting integrated model is used to predict the in vivo mechanical function and energetic state of the myocardium under resting conditions in each animal.

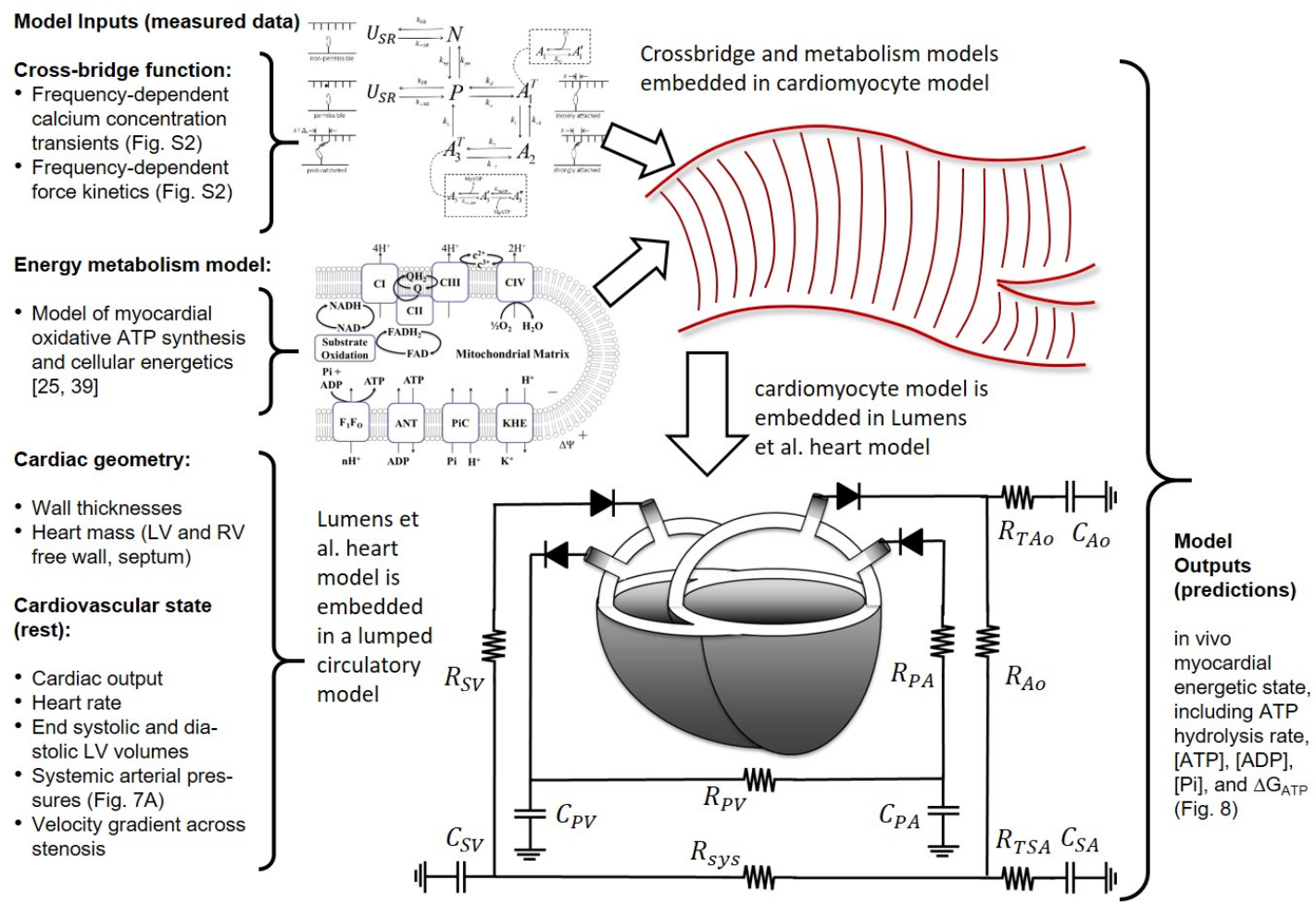

Figure 1. Multi-scale modeling of myocardial mechano-energetic function. The model integrates previously developed and validated models of cardiomyocyte dynamics Tewari et al. (2016a,b), myocardial energetics Bazil et al. (2016); Gao et al. (2019), whole-organ cardiac mechanics

Lumens et al. (2009) and a simple lumped parameter closed-loop circulatory system representing the systemic and pulmonary circuits. Data from multiple experimental modalities are used to identify model components for each individual animal in this study. The model predicts variables representing the in vivo myocardial energetic state, including ATP hydrolysis rate, $[\mathrm{ATP}],[\mathrm{ADP}],[\mathrm{Pi}]$, and the free energy of ATP hydrolysis DGATP in the LV myocardium for each individual animal. Figure reproduced from Lopez et al. (2020).

\section{Model of Cardiac Energy Metabolism}

\subsection{Model Variables:}

The cellular energy metabolism model is based on the mitochondrial oxidative phosphorylation model of Bazil et al. (2016). The model is governed by 29 ordinary differential equations governing mitochondrial membrane potential, metabolite species concentrations, and cation $\left(\mathrm{H}^{+}, \mathrm{K}^{+}\right.$, and $\mathrm{Mg}^{2+}$ ) concentrations in the mitochondrial matrix, inter-membrane space, and cytosol. Table 1 lists the state variables of the model, with a brief description, units used in the model, and the variable name used in the model codes. The original formulation of the model accounted for reactive oxygen species $\mathrm{O}_{2}^{--}$and $\mathrm{H}_{2} \mathrm{O}_{2}$, which are ignored here, and thus the model is modified accordingly from Bazil et al. (2016).

The governing equations for these variables are delineated below. 
Table 1. Energetics Model State Variables

\begin{tabular}{|c|c|c|c|}
\hline State Variable & Definition & Units & Variable name in code \\
\hline$\Delta \Psi$ & Mitochondrial membrane potential & $\mathrm{mV}$ & DPsi_im_to_matrix \\
\hline \multicolumn{4}{|c|}{ Mitochondrial Matrix State Variables } \\
\hline$[\mathrm{ATP}]_{x}$ & Total matrix ATP concentration & M & ATP_matrix \\
\hline$[\mathrm{ADP}]_{x}$ & Total matrix ADP concentration & M & ADP_matrix \\
\hline$[\mathrm{Pi}]_{x}$ & Total matrix Pi concentration & M & Pi_matrix \\
\hline$[\mathrm{NADH}]_{x}$ & Total matrix NADH concentration & M & $\mathrm{NADH}$ _matrix \\
\hline$[\mathrm{NAD}]_{x}$ & Total matrix NAD concentration & M & NAD_matrix \\
\hline$[\mathrm{UQH} 2]_{x}$ & Total matrix ubiquinol concentration & M & coQH2_matrix \\
\hline$[\mathrm{UQ}]_{x}$ & Total matrix ubiquinone concentration & M & coQ_matrix \\
\hline$\left[\mathrm{H}^{+}\right]_{x}$ & Matrix free proton concentration & M & h_matrix \\
\hline$\left[\mathrm{K}^{+}\right]_{x}$ & Matrix free potassium concentration & M & k_matrix \\
\hline$\left[\mathrm{Mg}^{2+}\right]_{x}$ & Matrix free magnesium concentration & M & m_matrix \\
\hline \multicolumn{4}{|c|}{ Intermembrane Space (IMS) State Variables } \\
\hline$\left[\mathrm{c}^{2+}\right]_{i}$ & Total cytochrome $\mathrm{c}^{2+}$ (reduced) concentration & M & cytocred_im \\
\hline$\left[\mathrm{c}^{3+}\right]_{i}$ & Total cytochrome $\mathrm{c}^{3+}$ (oxidized) concentration & M & cytocox_im \\
\hline$[\mathrm{ATP}]_{i}$ & Total IMS ATP concentration & M & ATP_matrix \\
\hline$[\mathrm{ADP}]_{i}$ & Total IMS ADP concentration & M & ADP_matrix \\
\hline$[\mathrm{AMP}]_{i}$ & Total IMS AMP concentration & M & AMP_matrix \\
\hline$[\mathrm{Pi}]_{i}$ & Total matrix Pi concentration & M & Pi_im \\
\hline$\left[\mathrm{H}^{+}\right]_{i}$ & IMS free proton concentration & M & h_im \\
\hline$\left[\mathrm{K}^{+}\right]_{i}$ & IMS free potassium concentration & M & k_im \\
\hline$\left[\mathrm{Mg}^{2+}\right]_{i}$ & IMS free magnesium concentration & M & m_im \\
\hline \multicolumn{4}{|c|}{ Cytosolic Space State Variables } \\
\hline$[\mathrm{ATP}]_{c}$ & Total cytosolic ATP concentration & M & ATP_C \\
\hline$[\mathrm{ADP}]_{c}$ & Total cytosolic ADP concentration & M & $A D P_{-} C^{-}$ \\
\hline$[\mathrm{AMP}]_{c}$ & Total cytosolic AMP concentration & M & $\mathrm{AMP}_{-} \mathrm{C}$ \\
\hline$[\mathrm{Pi}]_{c}$ & Total cytosolic Pi concentration & M & $\mathrm{Pi} \mathrm{C}_{\mathrm{C}}$ \\
\hline$[\mathrm{CrP}]_{c}$ & Total cytosolic phosphocreatine concentration & M & AMPP_c \\
\hline$[\mathrm{Cr}]_{c}$ & Total cytosolic creatine concentration & M & $\mathrm{Pi}_{-} \mathrm{C}$ \\
\hline$\left[\mathrm{H}^{+}\right]_{c}$ & cytosolic free proton concentration & M & $h_{-} \mathrm{c}$ \\
\hline$\left[\mathrm{K}^{+}\right]_{c}$ & cytosolic free potassium concentration & M & k_c \\
\hline$\left[\mathrm{Mg}^{2+}\right]_{c}$ & cytosolic free magnesium concentration & M & $\mathrm{m}_{-} \mathrm{c}$ \\
\hline
\end{tabular}

\subsection{Mitochondrial Membrane Potential:}

The potential difference across the mitochondrial inner membrane is governed by currents across the membrane:

$$
d \Delta \Psi / d t=\left(4 J_{C 1}+2 J_{C 3}+4 J_{C 4}-n H_{F 1 F 0} J_{F 1 F 0}-J_{A N T}-J_{H l e a k}\right) / C_{\text {mito }}
$$

where $J_{C 1}, J_{C 3}$, and $J_{C 4}$ are the complex I, III, and IV fluxes, which are associated with pumping 4, 2 , and 4 positive charges out of the matrix. The $F_{1} F_{0}$ ATPase turnover rate is $J_{F 1 F 0}$ and $n H_{F 1 F 0}$ $(=8 / 3)$ is the proton flux stoichiometric number associated with the synthesis of one ATP. The fluxes $J_{A N T}$ and $J_{\text {Hleak }}$ are the adenine nucleotide translocator and proton leak fluxes. 
2.3 Mitochondrial Matrix Metabolite State Variables:

Metabolite concentrations in the matrix are governed by:

$$
\begin{aligned}
d[\text { ATP }]_{x} / d t & =\left(J_{F 1 F 0}-J_{A N T}\right) / V o I_{x} \\
d[A D P]_{x} / d t & =\left(J_{A N T}-J_{F 1 F 0}\right) / V o I_{x} \\
d[P i]_{x} / d t & =\left(J_{P I C}-J_{F 1 F 0}\right) / V o I_{x} \\
d[N A D]_{x} / d t & =\left(J_{C 1}-J_{D H}\right) / V o I_{x} \\
d[N A D H]_{x} / d t & =\left(J_{D H}-J_{C 1}\right) / V o I_{x} \\
d[U Q]_{x} / d t & =\left(J_{C 3}-\alpha_{C 2} J_{D H}-J_{C 1}\right) / V o I_{x} \\
d\left[U Q H_{2}\right]_{x} / d t & =\left(-J_{C 3}+\alpha_{C 2} J_{D H}+J_{C 1}\right) / V o I_{x}
\end{aligned}
$$

where $V o I_{x}$ is the water volume of the mitochondrial matrix in units of volume of matrix water space per unit mitochondrial volume, the fluxes in the right-hand sides of these expressions are in units of moles per unit liter of mitochondrial volume per unit time, and are defined below. The coefficient $\alpha_{C 2}(=1 / 4)$ accounts for ubiquinone reduction via complex II.

\subsection{Inter-Membrane Space (IMS) Metabolite State Variables:}

Metabolite concentrations in the intermembrane space are governed by:

$$
\begin{aligned}
d\left[c^{2+}\right]_{i} / d t & =\left(-2 J_{C 4}+2 J_{C 3}\right) / V o l_{i} \\
d\left[c^{3+}\right]_{i} / d t & =\left(2 J_{C 4}-2 J_{C 3}\right) / V o l_{i} \\
d[A T P]_{i} / d t & =\left(J_{A N T}+J_{A T P P E R M}\right) / V o l_{i} \\
d[A D P]_{i} / d t & =\left(-J_{A N T}+J_{A D P P E R M}\right) / V o l_{i} \\
d[A M P]_{i} / d t & =\left(J_{A M P P E R M}\right) / V o l_{i} \\
d[P i]_{i} / d t & =\left(-J_{\text {PIC }}+J_{\text {PIPERM }}\right) / V o l_{i}
\end{aligned}
$$

where $V o l_{i}$ is the water volume of the mitochondrial inter-membrane space in units of volume of IMS water space per unit mitochondrial volume, the fluxes in the right-hand sides of these expressions are in units of moles per unit liter of mitochondrial volume per unit time, and are defined below.

\subsection{Cytosolic Metabolite State Variables:}

Metabolite concentrations in the cytosolic space are governed by:

$$
\begin{aligned}
d[\text { ATP }]_{c} / d t & =\left(-J_{\text {ATPase }}+J_{C K}+J_{A K}-J_{A T P P E R M} V_{R} m / V_{R} c\right) / V o l_{c} \\
d[\text { ADP }]_{c} / d t & =\left(+J_{A T P a s e}-J_{C K}-2 J_{A K}-J_{A D P P E R M} V_{R} m / V_{R} c\right) / V o l_{c} \\
d[\text { AMP }]_{c} / d t & =\left(+J_{A K}-J_{A M P P E R M} V_{R} m / V_{R} c\right) / V o l_{c} \\
d[P i]_{c} / d t & =\left(+J_{A T P a s e}-J_{P I P E R M} V_{R} m / V_{R} c\right) / V o l_{c} \\
d[C r P]_{c} / d t & =\left(-J_{C K}\right) / V o l_{c} \\
d[C r]_{c} / d t & =\left(+J_{A K}\right) / V o l_{c}
\end{aligned}
$$

where $V o I_{c}$ is the water volume of the cytosolic space in units of volume of cytosolic water space per unit cell volume. The fluxes in the right-hand sides of these expressions are defined below. The ratio $V_{R m} / V_{R c}$ is ratio of regional volume of the IMS to the cytosolic space. Since the $J_{A T P P E R M}, J_{A D P P E R M}, J_{A M P P E R M}$, and $J_{P I P E R M}$ fluxes are in units of mass per unit time per unit mitochondrial volume, the multiplication by $V_{R m} / V_{R c}$ converts the units to mass per unit time per unit cytosolic volume. The units of the other fluxes (cytosolic reaction fluxes) are mass per unit time per unit cytosolic volume.

\subsection{Cation Concentration State Variables:}

The governing equations for the cation $\left(\mathrm{H}^{+}, \mathrm{K}^{+}\right.$, and $\left.\mathrm{Mg}^{2+}\right)$ concentrations in the mitochondrial and extra-mitochondrial compartments are derived using the method outlined in Vinnakota et al. (2009). In brief, the equations account for rapid equilibria between conjugate bases of biochemical 
weak acid species (e.g., ATP ${ }^{4-}$ ) and cation bound species (e.g., HATP ${ }^{3-}$, KATP ${ }^{3-}$, and MgATP ${ }^{2-}$ ). The full set of equations is detailed in the supplementary material published with Bazil et al. (2016).

\subsection{Energetic Model Fluxes:}

The fluxes on the right-hand sides of Equations (1,2,3, and 4) are defined in Table 2.

Table 2. Energetics Model Reaction and Transport Fluxes

\begin{tabular}{|c|c|c|c|}
\hline Flux & Definition & Units & Variable name in code \\
\hline$J_{C 1}$ & $\begin{array}{l}\text { Electron transport } \\
\text { chain Complex I flux }\end{array}$ & mole. $\sec ^{-1} \cdot(\text { L mito })^{-1}$ & J_ETC1_im_to_matrix \\
\hline$J_{C 3}$ & $\begin{array}{l}\text { Electron transport } \\
\text { chain Complex III flux }\end{array}$ & mole $\cdot \sec ^{-1} \cdot(\text { L mito })^{-1}$ & J_ETC3_im_to_matrix \\
\hline$J_{C 4}$ & $\begin{array}{l}\text { Electron transport } \\
\text { chain Complex IV flux }\end{array}$ & mole $\cdot \sec ^{-1} \cdot(\text { L mito })^{-1}$ & J_ETC4_im_to_matrix \\
\hline$J_{F 1 F 0}$ & $\begin{array}{l}\text { Mitochondrial } F_{1} F_{0} \\
\text { ATPase flux }\end{array}$ & mole $\cdot \sec ^{-1} \cdot(\text { L mito })^{-1}$ & J_F1FOATPASE_im_to_matrix \\
\hline$J_{A N T}$ & $\begin{array}{l}\text { Adenine nucleotide } \\
\text { translocase flux }\end{array}$ & mole $\cdot \sec ^{-1} \cdot(\text { L mito })^{-1}$ & J_ANT_im_to_matrix \\
\hline$J_{\text {Hleak }}$ & Proton leak flux & mole $\cdot \sec ^{-1} \cdot(\text { L mito })^{-1}$ & J_HLEAK_im_to_matrix \\
\hline$J_{D H}$ & $\begin{array}{l}\text { Rate of NADH produc- } \\
\text { tion }\end{array}$ & mole $\cdot \sec ^{-1} \cdot(\text { L mito })^{-1}$ & J_DH_matrix \\
\hline$J_{P I C}$ & $\begin{array}{l}\text { Mitochondrial phos- } \\
\text { phate carrier flux }\end{array}$ & mole $\cdot \sec ^{-1} \cdot(\text { L mito })^{-1}$ & J_PIC_im_to_matrix \\
\hline$J_{A T P P E R M}$ & $\begin{array}{lr}\text { Mitochondrial } & \text { outer } \\
\text { membrane } & \text { ATP } \\
\text { permeation } & \end{array}$ & mole $\cdot \sec ^{-1} \cdot(\text { L mito })^{-1}$ & J_ATPPERM_cytoplasm_to_im \\
\hline$J_{A D P P E R M}$ & $\begin{array}{lr}\text { Mitochondrial } & \text { outer } \\
\text { membrane } & \text { ADP } \\
\text { permeation } & \end{array}$ & mole $\cdot \sec ^{-1} \cdot(\text { L mito })^{-1}$ & J_ADPPERM_cytoplasm_to_im \\
\hline$J_{A M P P E R M}$ & $\begin{array}{ll}\text { Mitochondrial } & \text { outer } \\
\text { membrane } & \text { AMP } \\
\text { permeation } & \end{array}$ & mole $\cdot \sec ^{-1} \cdot(\text { L mito })^{-1}$ & J_AMPPERM_cytoplasm_to_im \\
\hline$J_{P I P E R M}$ & $\begin{array}{l}\text { Mitochondrial outer } \\
\text { membrane Pi perme- } \\
\text { ation }\end{array}$ & mole $\cdot \sec ^{-1} \cdot(\text { L mito })^{-1}$ & J_PIPERM_cytoplasm_to_im \\
\hline$J_{C K}$ & $\begin{array}{l}\text { Cytosolic creatine ki- } \\
\text { nase flux }\end{array}$ & mole $\cdot \sec ^{-1} \cdot(\text { L cytosol })^{-1}$ & J_CK_cytoplasm \\
\hline$J_{A K}$ & $\begin{array}{l}\text { Cytosolic adenylate ki- } \\
\text { nase flux }\end{array}$ & mole $\cdot \sec ^{-1} \cdot(\text { L cytosol })^{-1}$ & J_AK_cytoplasm \\
\hline$J_{\text {ATPase }}$ & $\begin{array}{l}\text { Cytosolic ATP hydrol- } \\
\text { ysis flux }\end{array}$ & mole $\cdot \sec ^{-1} \cdot(\text { L cytosol })^{-1}$ & J_ATPASE_cytoplasm \\
\hline
\end{tabular}

The mathematical expressions for these fluxes are detailed in Bazil et al. (2016).

\subsection{Implementation in Multiscale Model:}

The cellular energetics model is implemented in a MATLAB script called EnergeticsModelScript.m. This script is used to predict cytosolic [ATP], [ADP], [AMP], [Pi], [Cr], and [CrP] at a specified input rate of cytosolic ATP hydrolysis. Input and output arguments for the script are listed below in Tables 3 and 4.

\section{Cardiomyocyte Mechanics Model}

\subsection{Model Variables and Equations:}

A cardiomyocyte mechanics model based on the models of Tewari et al. (2016a,b) and Campbell et al. (2018) is used to simulate the active and passive components of myocardial wall tension 
Table 3. Input arguments for cellular energetics model

\begin{tabular}{|c|c|c|c|}
\hline Input variable & Definition & $\begin{array}{l}\text { Units used in } \\
\text { code }\end{array}$ & Values \\
\hline $\begin{array}{l}\text { TAN } \\
\text { CRtot }\end{array}$ & $\begin{array}{l}\text { total adenine nu- } \\
\text { cleotide pool } \\
\text { total creatine pool }\end{array}$ & $\begin{array}{l}\text { mole } \cdot(\text { I cell })^{-1} \\
\text { mole } \cdot(\text { I cell })^{-1}\end{array}$ & $\begin{array}{l}0.0071-0.0086 \text { for sham } \\
0.0052-0.0085 \text { for TAC } \\
0.0267-0.0330 \text { for sham } \\
0.0146-0.0278 \text { for TAC }\end{array}$ \\
\hline TEP & $\begin{array}{l}\text { total exchangeable } \\
\text { phosphate pool }\end{array}$ & mole.(I cell $)^{-1}$ & $\begin{array}{l}0.0247-0.0298 \text { for sham } \\
0.0181-0.0293 \text { for TAC }\end{array}$ \\
\hline Ox_capacity & $\begin{array}{l}\text { oxidative capacity (rel- } \\
\text { ative to control) }\end{array}$ & unitless & $\begin{array}{l}0.834-1.1526 \text { for sham } \\
0.5287-0.9755 \text { for TAC }\end{array}$ \\
\hline x_ATPase & ATP hydrolysis rate & $\begin{array}{l}\text { mmole } \cdot \sec ^{-1} \cdot(\mathrm{I} \\
\text { cell })^{-1}\end{array}$ & $\begin{array}{l}0.9301-1.392 \text { for sham } \\
0.6758-1.410 \text { for TAC }\end{array}$ \\
\hline
\end{tabular}

Table 4. Output arguments for cellular energetics model

\begin{tabular}{|c|c|c|c|}
\hline Output variable & Definition & $\begin{array}{l}\text { Units used in } \\
\text { code }\end{array}$ & Values \\
\hline MgATP_cytoplasm & cytosolic [MgATP] & mmole.(I & $7.2145-9$. \\
\hline MgADP_cytoplasm & cytosolic [MgADP] & $\begin{array}{l}\text { tosol water })^{-1} \\
\text { mmole.(l cy- } \\
\text { tosol water) })^{-1}\end{array}$ & $\begin{array}{l}4.9384-9.0634 \text { for TAC } \\
0.0467-0.0598 \text { for sham } \\
0.0274-0.0549 \text { for TAC }\end{array}$ \\
\hline fPi_cytoplasm & $\begin{array}{l}\text { cytosolic unchelated } \\
{[\mathrm{Pi}]}\end{array}$ & $\begin{array}{l}\text { mmole.(l cy- } \\
\text { tosol water })^{-1}\end{array}$ & $\begin{array}{l}0.4393-1.3073 \text { for sham } \\
1.1437-1.6650 \text { for TAC }\end{array}$ \\
\hline MVO2_tissue & $\begin{array}{l}\text { oxygen consumption } \\
\text { rate }\end{array}$ & $\begin{array}{l}\mu \text { mole } \cdot \min ^{-1} \cdot(\mathrm{g} \\
\text { tissue })^{-1}\end{array}$ & $\begin{array}{l}7.617-12.380 \text { for sham } \\
6.9104-12.450 \text { for TAC }\end{array}$ \\
\hline dGrATPase & $\begin{array}{l}\text { ATP hydrolysis free } \\
\text { energy }\end{array}$ & $\mathrm{kJ} \cdot \mathrm{mole}^{-1}$ & $\begin{array}{l}-(66.054-62.71) \text { for sham } \\
-(63.574-61.44) \text { for TAC }\end{array}$ \\
\hline PCrATP & CrP/ATP ratio & unitless & $\begin{array}{l}1.817-2.324 \text { for sham } \\
1.4985-1.897 \text { for TAC }\end{array}$ \\
\hline ATP_cyto & cytosolic total [ATP] & 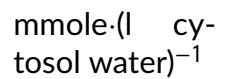 & $\begin{array}{l}\text { 8.733-11.438 for sham } \\
5.983-10.959 \text { for TAC }\end{array}$ \\
\hline ADP_cyto & cytosolic total [ADP] & $\begin{array}{l}\text { mmole }(\mathrm{ll} \quad \mathrm{cy}- \\
\text { tosol water }^{-1}\end{array}$ & $\begin{array}{l}0.1164-0.1486 \text { for sham } \\
0.0682-0.1359 \text { for TAC }\end{array}$ \\
\hline Pi_cyto & cytosolic total $[\mathrm{Pi}]$ & 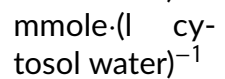 & $\begin{array}{l}0.7403-2.197 \text { for sham } \\
1.9225-2.798 \text { for TAC }\end{array}$ \\
\hline
\end{tabular}

used in the heart model ( $\$ 3$, below) and to determine the ATP hydrolysis rate used in the energy metabolism model (\$1, above). The components of the model are illustrated in Fig. 2.

The five states in the cross-bridge model correspond to: the non-permissible (no calcium bound) state $N$, the permissible (calcium-bound) state $P$, loosely attached state $A_{1}$, strongly attached state $A_{2}$, and post-ratcheted state $A_{3}$. The attached states are distributed over a continuum of cross-bridge strain. To numerically simulate the model a moment-expansion approach is used where ordinary differential equations for the first three moments of the probability distributions of strain of each of the attached states are simulated.

The state variables for the cross-bridge model are tabulated below. 
Table 5. State variables in cross-bridge model

\begin{tabular}{|c|c|c|c|}
\hline $\begin{array}{l}\text { State } \\
\text { Variable }\end{array}$ & Definition & Units used in code & $\begin{array}{l}\text { Variable name } \\
\text { in code }\end{array}$ \\
\hline$p_{1}^{0}$ & $\begin{array}{l}\text { The } 0^{\text {th }} \text { moment of state } \mathrm{A} 1 \text { strain } \\
\text { probability distribution. Equal to the } \\
\text { proportion of cross-bridges in state } \mathrm{A} 1 \text {. }\end{array}$ & unitless & P1_0 \\
\hline$p_{1}^{1}$ & $\begin{array}{l}\text { The } 1^{\text {st }} \text { moment of state } \mathrm{A} 1 \text { strain } \\
\text { probability distribution. }\end{array}$ & $\mu \mathrm{m}$ & P1_1 \\
\hline$p_{1}^{2}$ & $\begin{array}{l}\text { The } 2^{\text {nd }} \text { moment of state } A 1 \text { strain } \\
\text { probability distribution. }\end{array}$ & $\mu \mathrm{m}^{2}$ & P1_2 \\
\hline$p_{2}^{0}$ & $\begin{array}{l}\text { The } 0^{\text {th }} \text { moment of state } A 2 \text { strain } \\
\text { probability distribution. Equal to the } \\
\text { proportion of cross-bridges in state } A 2 \text {. }\end{array}$ & unitless & $\mathrm{P} 2 \_0$ \\
\hline$p_{2}^{1}$ & $\begin{array}{l}\text { The } 1^{\text {st }} \text { moment of state } A 2 \text { strain } \\
\text { probability distribution. }\end{array}$ & $\mu \mathrm{m}$ & P2_1 \\
\hline$p_{2}^{2}$ & $\begin{array}{l}\text { The } 2^{\text {nd }} \text { moment of state } \mathrm{A} 2 \text { strain } \\
\text { probability distribution. }\end{array}$ & $\mu \mathrm{m}^{2}$ & P2_2 \\
\hline$p_{3}^{0}$ & $\begin{array}{l}\text { The } 0^{\text {th }} \text { moment of state } A 3 \text { strain } \\
\text { probability distribution. Equal to the } \\
\text { proportion of cross-bridges in state } A 3 \text {. }\end{array}$ & unitless & P3_0 \\
\hline$p_{3}^{1}$ & $\begin{array}{l}\text { The } 1^{\text {st }} \text { moment of state } A 3 \text { strain } \\
\text { probability distribution. }\end{array}$ & $\mu \mathrm{m}$ & P3_1 \\
\hline$p_{3}^{2}$ & $\begin{array}{l}\text { The } 2^{\text {nd }} \text { moment of state } A 3 \text { strain } \\
\text { probability distribution. }\end{array}$ & $\mu \mathrm{m}^{2}$ & P3_2 \\
\hline$N$ & Non-permissible XB state & unitless & $\mathrm{N}$ \\
\hline$U_{N R}$ & Non relaxed state & unitless & U_NR \\
\hline
\end{tabular}

The equations used to simulate the cross-bridge model are

$$
\begin{aligned}
& \frac{d p_{1}^{0}}{d t}=k_{a} P(t) U_{N R} O V_{t h i c k}-\tilde{k_{d}} p_{1}^{0}-\tilde{k_{1}}\left(\left(p_{1}^{0}-\alpha_{1} p_{1}^{1}+1 / 2 \alpha_{1}^{2} p_{1}^{2}\right)+k_{-1}\left(p_{2}^{0}+\alpha_{1} p_{2}^{1}+\frac{1}{2} \alpha_{1}^{2} p_{2}^{2}\right)\right. \\
& \frac{d p_{1}^{1}}{d t}=v p_{1}^{0}-\tilde{k_{d}} p_{1}^{1}-\tilde{k_{1}}\left(p_{1}^{1}-\alpha_{1} p_{1}^{2}\right)+k_{-1}\left(p_{2}^{1}+\alpha_{1} p_{2}^{2}\right) \\
& \frac{d p_{1}^{2}}{d t}=2 v p_{1}^{1}-\tilde{k_{d}} p_{1}^{2}-\tilde{k_{1}} p_{1}^{2}+k_{-1} p_{2}^{2} \\
& \frac{d p_{2}^{0}}{d t}=\tilde{k_{1}}\left(p_{1}^{0}-\alpha_{1} p_{1}^{1}+\frac{1}{2} \alpha_{1}^{2} p_{1}^{2}\right)-k_{-1}\left(p_{2}^{0}+\alpha_{1} p_{2}^{1}+\frac{1}{2} \alpha_{1}^{2} p_{2}^{2}\right)-k_{2}\left(p_{2}^{0}-\alpha_{2} p_{2}^{1}+\frac{1}{2} \alpha_{2}^{2} p_{2}^{2}\right)+\widetilde{k_{-2}} p_{3}^{0} \\
& \frac{d p_{2}^{1}}{d t}=v p_{2}^{0}+\tilde{k_{1}}\left(p_{1}^{1}-\alpha_{1} p_{1}^{2}\right)-k_{-1}\left(p_{2}^{1}+\alpha_{1} p_{2}^{2}\right)-k_{2}\left(p_{2}^{1}-\alpha_{2} p_{2}^{2}\right)+\widetilde{k_{-2}} p_{3}^{1} \\
& \frac{d p_{2}^{2}}{d t}=2 v p_{2}^{1}+\tilde{k_{1}} p_{1}^{2}-k_{-1} p_{2}^{2}-k_{2} p_{2}^{2}+\widetilde{k_{-2}} p_{3}^{2} \\
& \frac{d p_{3}^{0}}{d t}=k_{2}\left(p_{2}^{0}-\alpha_{2} p_{2}^{1}+\frac{1}{2} \alpha_{2}^{2} p_{2}^{2}\right)-\widetilde{k_{-2}} p_{3}^{0}-\tilde{k_{3}}\left(p_{3}^{0}-\alpha_{3} s_{3}^{2} p_{3}^{0}+2 \alpha_{3} s_{3} p_{3}^{1}+p_{3}^{2}\right) \\
& \frac{d p_{3}^{1}}{d t}=v p_{3}^{0}+k_{2}\left(p_{2}^{1}-\alpha_{2} p_{2}^{2}\right)-\widetilde{k_{-2}} p_{3}^{1}-\tilde{k_{3}}\left(p_{3}^{1}-\alpha_{3} s_{3}^{2} p_{3}^{1}+2 \alpha_{3} s_{3} p_{3}^{2}\right) \\
& \frac{d p_{3}^{2}}{d t}=2 v p_{3}^{1}+k_{2} p_{2}^{2}-\tilde{k_{-2}} p_{3}^{2}-\tilde{k_{3}}\left(p_{3}^{2}+\alpha_{3} s_{3}^{2} p_{3}^{2}\right)
\end{aligned}
$$

where $v$ is the velocity of sliding $(v=d S L / d t$ where $S L$ is the sarcomere length, used below in the heart model of Section 4).

Metabolite concentrations affect the apparent rate constants in the model via the following 
relations:

$$
\begin{aligned}
\tilde{k_{d}} & =k_{d} \frac{[\mathrm{Pi}] / K_{P i}}{1+[\mathrm{Pi}] / K_{P i}} \\
\tilde{k_{1}} & =k_{1} \frac{1}{1+[\mathrm{Pi}] / K_{P i}} \\
\tilde{k_{-2}} & =k_{-2} \frac{[\mathrm{MgADP}] / K_{M g A D P}}{1+[\mathrm{MgADP}] / K_{M g A D P}+[\mathrm{MgATP}] / K_{M g A T P}} \\
\tilde{k_{3}} & =k_{3} \frac{[\mathrm{MgATP}] / K_{M g A T P}}{1+[\mathrm{MgADP}] / K_{M g A D P}+[\mathrm{MgATP}] / K_{M g A T P}}
\end{aligned}
$$

A detailed description of the moment expansion and associated equations is given in Tewari et al. (2016a).

A

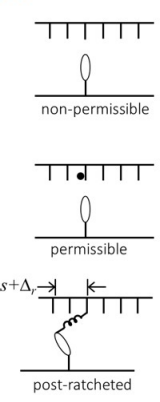

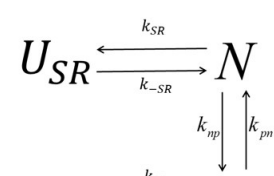

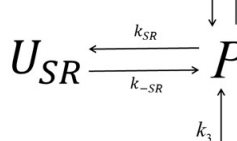

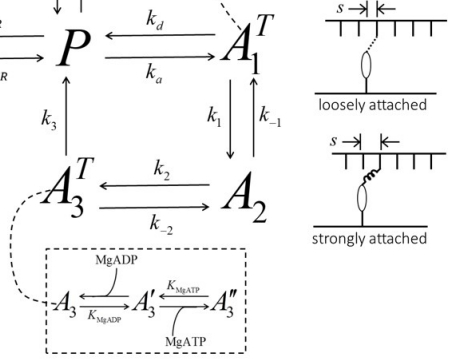

B
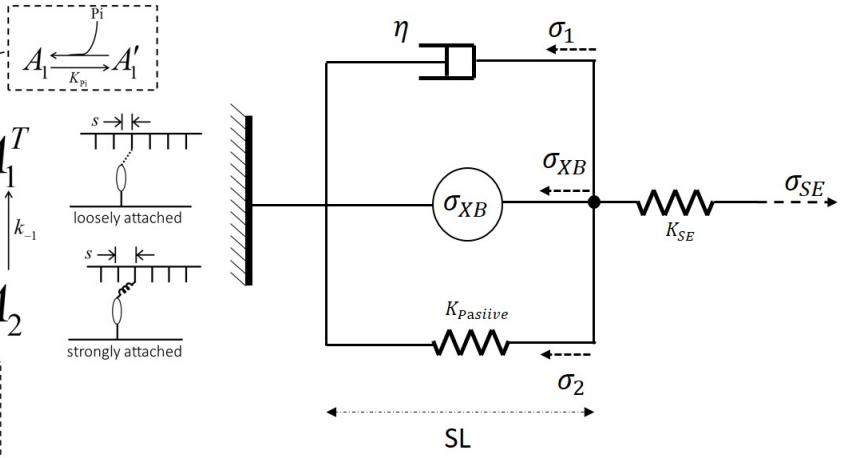

Figure 2. Cardiomyocyte mechanics model. The multi-scale strain-dependent model for the cross-bridge cycle is illustrated in panel A. The integration of the cross-bridge force $\left(\sigma_{X B}\right)$ into a model of muscle mechanics is illustrated in panel B.

\subsection{Calcium activation:}

The calcium activation model is adopted from Campbell et al. (2018) model with minor modifications. The equations for calcium-mediated transition from the $\mathrm{N}$ to the $\mathrm{P}$ state are:

$$
\begin{aligned}
J_{\text {on }} & =k_{\text {on }}\left[\mathrm{Ca}^{2+}\right] N\left(1+k_{\text {coop }}(1-N)\right) \\
J_{\text {off }} & =k_{\text {off }} P\left(1+k_{\text {coop }} N\right)
\end{aligned}
$$

The term $k_{\text {coop }}(1-N)$ is representative of cooperative activation. The variable $N$ represents the non-permissible state:

$$
\begin{aligned}
P & =1-N-p_{1}^{0}-p_{2}^{0}-p_{3}^{0} \\
\frac{d N}{d t} & =-J_{\text {on }}+J_{\text {off }}
\end{aligned}
$$

where $P$ is the permissible (calcium-bound).

\subsection{Super-relaxed state:}

The Campbell et al. model for calcium activation includes a transition between a super-relaxed and not relaxed state.

$$
\begin{array}{r}
U_{S R} \leftrightharpoons U_{N} R \\
U_{S R}+U_{N R}=1
\end{array}
$$

where the transition from super-relaxed $\left(U_{S R}\right)$ to non-relaxed $\left(U_{N R}\right)$ state is force-dependent:

$$
\frac{d U_{N R}}{d t}=k_{S R}\left(1+k_{\text {force }} \sigma_{X B}\right) U_{S R}-k_{-S R} U_{N R} .
$$


where $\sigma_{X B}$, is active contractile force and formulated in equation 12 .

\subsection{Overlap function:}

Following Rice et al. (2008) the fractional overlap between thin and thick filament is represented as follows:

$$
O V_{Z \text {-axis }}=\min \left(L_{\text {thick }} / 2, S L / 2\right),
$$

where $O V_{Z \text {-axis }}$ is the overlap region closest to the Z-axis,

$$
O V_{M-l i n e}=\max \left(S L / 2-\left(S L-L_{t h i n}\right), L_{\text {bare }} / 2\right),
$$

where $O V_{M-l i n e}$ is the overlap region closest to the $M$-line. The length of overlap $L O V$ is computed as following:

$$
L O V=O V_{Z-a x i s}-O V_{M-l i n e}
$$

Using length of overlap LOV, fraction of thick filament overlap is computed as following:

$$
O V_{\text {thick }}=2 L O V /\left(L_{\text {thick }}-L_{\text {bare }}\right) \text {. }
$$

Here $S L$ is the length of sarcomere, $L_{\text {thick }}, L_{t h i n}, L_{\text {bare }}$ are the length of thick filament, bare region of the thick filament and, the length of the thin filament.

Table 6. Sarcomere overlap function parameters

\begin{tabular}{llll}
\hline Parameter & Definition & Value and units & Parameter name in code \\
\hline$L_{t}$ hin & thin filament length & $1200 \mathrm{~nm}$ & L_thin \\
$L_{t}$ hick & thick filament length & $1670 \mathrm{~nm}$ & L_thick \\
$L_{b}$ are & bare length of the thick filament & $100 \mathrm{~nm}$ & L_hbare \\
$O V_{Z-a x i s}$ & overlap region closest to the Z-axis & $\mathrm{nm}$ & sovr_ze \\
$O V_{M-l i n e}$ & overlap region closest to the M-line & $\mathrm{nm}$ & sovr_cle \\
LOV & length of overlap & $\mathrm{nm}$ & L_sovr \\
OV $V_{\text {thick }}$ & fraction of thick filament overlap & unitless & N_overlap \\
\hline
\end{tabular}

\subsection{Active and passive force:}

The active force generated by cross-bridges is computed from contributions from pre- and postratcheted states:

$$
\sigma_{X B}(t)=O V_{\text {thick }}\left(k_{\text {stiff }, 1}\left(p_{2}^{2}+p_{3}^{2}\right)+k_{\text {stiff }, 2} \Delta r p_{3}^{0}\right)
$$

where $k_{\text {stiff }, 1}$ and $k_{\text {stiff }, 2)}$ are stiffness constants, $\Delta r$ is the cross bridge strain associated with ratcheting deformation. The full muscle model (Fig. 2) includes contributions from the active force generated by the cross-bridge mechanics, the viscous and passive forces associated with the muscle, $F_{1}$ and $F_{2}$, and a series element force $F_{S E}$. Overall force balance for the model yields

$$
\sigma_{S E}(t)=\sigma_{X B}(t)+\sigma_{1}(t)+\sigma_{2}(t) .
$$

The stress contributed from the dashpot (viscous) is determined from the rate of change of sarcomere length.

$$
\sigma_{1}=\eta \frac{d S L}{d t}
$$

The passive force $\sigma_{2}$ is a function of sarcomere length and is calculated

$$
\sigma_{2}(S L)=k_{\text {passive }}\left(S L-S L_{\text {rest }}\right)+\sigma_{\text {Passive }_{c} \text { ollagen }}(S L)
$$


where $k_{\text {passive }}$ is the stiffness parameters for the passive force, $S L_{\text {rest }}$ is the sarcomere rest length, and the passive force exerted by collagen is adopted from Rice et al. (2008).

$$
\sigma_{\text {Passive }_{c} \text { ollagen }}(S L)= \begin{cases}P \text { con }_{\text {collagen }}\left[e^{P E x p_{\text {collagen }}\left(S L-S L_{\text {collagen }}\right)}-1\right] & \text { if } S L>S L_{\text {collagen }} \\ 0 & \text { otherwise }\end{cases}
$$

where $P$ con collagen $=0.01$ (unitless) is the scale factor for passive force contributed by collagen. $P E x p_{\text {collagen }}=70 \mu \mathrm{m}^{-1}$ is a model parameter and $S L_{\text {collagen }}=2.25 \mu \mathrm{m}$ is the minimum length threshold at which collagen starts to exert force on sarcomere.

\subsection{Model Parameters:}

Certain parameters from the cross-bridge and calcium-activation models of Tewari et al. (2016a,b) and Campbell et al. (2018) were re-estimated to match data from Janssen et al. (2002) on calcium transients and force-generation in isolated rat cardiac trabeculae. In brief, experiments were conducted at $37^{\circ} \mathrm{C}$. Calcium transients (Fig. 3) were measured at different stimulation frequencies at fixed sarcomere length $\mathrm{SL}=2.2 \mu \mathrm{m}$. Isometric tension time courses were measured at different stimulation frequencies and sarcomere lengths. Fig. 3 shows data on peak developed tension $\left(T_{d e v}\right)$ as a function of $S L$ at stimulation frequency of $4 \mathrm{~Hz}$; and data on relaxation time from peak to $50 \%$ of peak tension (RT50); peak developed tension $\left(T_{d e v}\right)$ and time to peak tension (TTP) as function of $S L$.

Model simulations were fit to these data to estimate unknown parameters in the calcium activation and cross-bridge kinetics components of the model. Specifically, parameters adjusted to values different from those in the original publication are indicated below in Table 7.

A

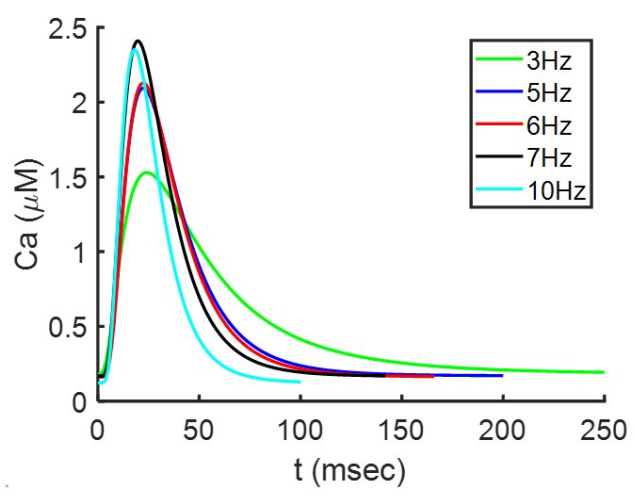

B
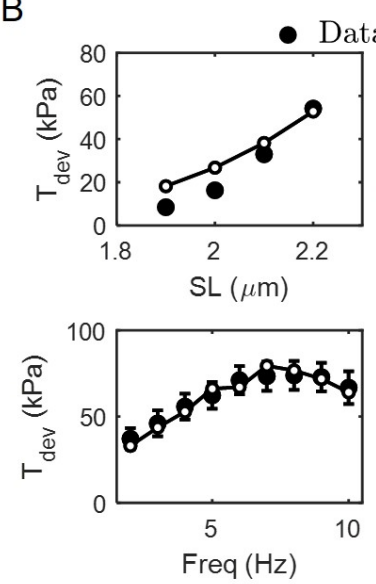
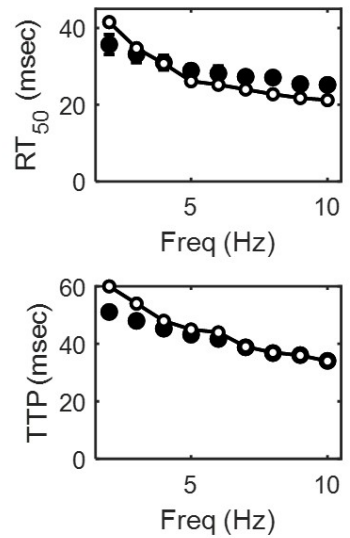

Figure 3. Crossbridge model parameters estimation. For $S L=1.9 \mu \mathrm{m}$ the $C a_{50}=5.89$ and Hill coefficient $n=4.63$ and for $S L=2.3 \mu \mathrm{m}$ the $C a_{50}=6.001$ and Hill coefficient $n=4.47$. Error bars shown in panel (B) represent standard error from the $\mathrm{n}=9$ data-set Janssen et al. (2002).

\section{Heart Model}

\subsection{Model Variables and Equations:}

A modified version of the Lumens et al. (2009) TriSeg model is used to simulate left- and rightventricular mechanics, based on the implementation of Tewari et al. (2016b). Tension development in each of the left-ventricular free wall, septum, and right-ventricular free wall is simulated using a cell mechanics model to represent each of these segments. From Eq. (14) the rates of change of sarcomere length in these three segments is given by 
Table 7. Model parameters for cross bridge model

\begin{tabular}{|c|c|c|c|c|}
\hline Parameter & Definition & $\begin{array}{l}\text { Value and } \\
\text { units }\end{array}$ & $\begin{array}{l}\text { Parameter } \\
\text { name in code }\end{array}$ & Reference \\
\hline$k_{\text {stiff }, 1}$ & $\begin{array}{l}\text { Stiffness constant due to } \\
\text { myosin-actin interaction }\end{array}$ & $\begin{array}{l}13013 \\
\mathrm{mmHg} / \mu \mathrm{m}\end{array}$ & kstiff1 & $\begin{array}{l}\text { Fit to data in } \\
\text { Fig. } 3\end{array}$ \\
\hline$k_{\text {stiff }, 2}$ & $\begin{array}{l}\text { Stiffness constant due to work- } \\
\text { ing stroke of XBs }\end{array}$ & $\begin{array}{l}341590 \\
\mathrm{mmHg} / \mu \mathrm{m}\end{array}$ & kstiff2 & $\begin{array}{l}\text { Fit to data in } \\
\text { Fig. } 3\end{array}$ \\
\hline$k_{\text {passive }}$ & Passive stiffness constant & $\begin{array}{l}25 \\
\mathrm{mmHg} / \mu \mathrm{m}\end{array}$ & k_passive & $\begin{array}{l}\text { Fit to data in } \\
\text { Fig. } 3\end{array}$ \\
\hline$S L_{\text {rest }}$ & $\begin{array}{l}\text { Sarcomere length at which pas- } \\
\text { sive force is zero }\end{array}$ & $1.8 \mu \mathrm{m}$ & SL_rest_pas & $\begin{array}{l}\text { Campbell et al } \\
(2018)\end{array}$ \\
\hline$\alpha_{1}$ & Strain-dependency parameter & $10 \mu \mathrm{m}^{-1}$ & alpha1 & $\begin{array}{l}\text { Tewari et al } \\
(2016 b)\end{array}$ \\
\hline$\alpha_{2}$ & Strain-dependency parameter & $9 \mu \mathrm{m}^{-1}$ & alpha2 & $\begin{array}{l}\text { Tewari et al } \\
(2016 b)\end{array}$ \\
\hline$\alpha_{3}$ & Strain-dependency parameter & $5.93 \mu \mathrm{m}^{-2}$ & alpha3 & $\begin{array}{l}\text { Fit to data in } \\
\text { Fig. } 3\end{array}$ \\
\hline$s_{3}$ & Strain-dependency parameter & $9.9 \times 10^{-3} \mu \mathrm{m}$ & s3 & $\begin{array}{l}\text { Tewari et al } \\
(2016 b)\end{array}$ \\
\hline$k_{\text {coop }}$ & $\begin{array}{l}\text { Strength of thin filament cooper- } \\
\text { ativity }\end{array}$ & 1.857 & K_coop & $\begin{array}{l}\text { Fit to data in } \\
\text { Fig. } 3\end{array}$ \\
\hline$k_{\text {on }}$ & $\begin{array}{l}\text { Rate constant of Ca binding to } \\
\text { troponin } \mathrm{C}\end{array}$ & $101.2 \mu \mathrm{M}^{-1} \cdot \mathrm{s}^{-1}$ & k_on & $\begin{array}{l}\text { Fit to data in } \\
\text { Fig. } 3\end{array}$ \\
\hline$k_{o f f}$ & $\begin{array}{l}\text { Rate constant of } \mathrm{Ca} \text { unbinding } \\
\text { from troponin } \mathrm{C}\end{array}$ & $101.2 \mathrm{~s}^{-1}$ & k_off & $\begin{array}{l}\text { Fit to data in } \\
\text { Fig. } 3\end{array}$ \\
\hline$k_{\text {force }}$ & $\begin{array}{l}\text { Force-dependent rate constant } \\
\text { of super relax transition }\end{array}$ & $\begin{array}{l}1.169 \times 10^{-3} \\
\mathrm{~N}^{-1} \cdot \mathrm{m}^{-2}\end{array}$ & kforce & $\begin{array}{l}\text { Fit to data in } \\
\text { Fig. } 3\end{array}$ \\
\hline$k_{S R}$ & $\begin{array}{l}\text { Rate constant of force- } \\
\text { dependent super relax transition }\end{array}$ & $14.44 \mathrm{~s}^{-1}$ & $\mathrm{ksr}$ & $\begin{array}{l}\text { Fit to data in } \\
\text { Fig. } 3\end{array}$ \\
\hline$k_{-S R}$ & $\begin{array}{l}\text { Rate constant of force- } \\
\text { dependent super relax transition }\end{array}$ & $50.03 \mathrm{~s}^{-1}$ & kmsr & $\begin{array}{l}\text { Fit to data in } \\
\text { Fig. } 3\end{array}$ \\
\hline$k_{M g A T P}$ & [MgATP] dissociation constant & $489.7 \mu \mathrm{M}$ & $\mathrm{K}_{-} \mathrm{T}$ & $\begin{array}{l}\text { Tewari et al } \\
(2016 b)\end{array}$ \\
\hline$k_{M g A D P}$ & [MgADP] dissociation constant & $194.0 \mu \mathrm{M}$ & K_D & $\begin{array}{l}\text { Tewari et al } \\
(2016 b)\end{array}$ \\
\hline$k_{P i}$ & [Pi] dissociation constant & $4.0 \mathrm{mM}$ & K_Pi & $\begin{array}{l}\text { Tewari et al } \\
(2016 \mathrm{~b})\end{array}$ \\
\hline$k_{a}$ & Myosin-actin rate of attachment & $559.6 \mathrm{~s}^{-1}$ & ka & $\begin{array}{l}\text { Fit to data in } \\
\text { Fig. } 3\end{array}$ \\
\hline$k_{d}$ & $\begin{array}{l}\text { Myosin-actin rate of un- } \\
\text { attachment }\end{array}$ & $304.7 \mathrm{~s}^{-1}$ & $\mathrm{kd}$ & $\begin{array}{l}\text { Fit to data in } \\
\text { Fig. } 3\end{array}$ \\
\hline$k_{1}$ & Transition rate constant & $112.4 \mathrm{~s}^{-1}$ & $\mathrm{k} 1$ & $\begin{array}{l}\text { Fit to data in } \\
\text { Fig. } 3\end{array}$ \\
\hline$k_{-1}$ & $\begin{array}{l}\text { Rate of strongly-bound to } \\
\text { weakly-bound transition }\end{array}$ & $21.30 \mathrm{~s}^{-1}$ & $\mathrm{~km} 1$ & $\begin{array}{l}\text { Tewari et al } \\
(2016 b)\end{array}$ \\
\hline$k_{2}$ & Rate of ratcheting & $811.7 \mathrm{~s}^{-1}$ & k2 & $\begin{array}{l}\text { Tewari et al } \\
(2016 b)\end{array}$ \\
\hline$k_{-2}$ & Reverse ratcheting rate & $43.25 \mathrm{~s}^{-1}$ & $\mathrm{~km} 2$ & $\begin{array}{l}\text { Tewari et al } \\
(2016 b)\end{array}$ \\
\hline$k_{3}$ & Myosin-actin detachment rate & $144.6 \mathrm{~s}^{-1}$ & k3 & $\begin{array}{l}\text { Fit to data in } \\
\text { Fig. } 3\end{array}$ \\
\hline
\end{tabular}

$$
\begin{aligned}
\frac{d S L_{R V}}{d t} & =\frac{\sigma_{S E, R V}-\sigma_{2}\left(S L_{R V}\right)-\lambda_{X B} \sigma_{X B, R V}(t)}{\eta} \\
\frac{d S L_{L V}}{d t} & =\frac{\sigma_{S E, L V}-\sigma_{2}\left(S L_{L V}\right)-\lambda_{X B} \sigma_{X B, L V}(t)}{\eta} \\
\frac{d S L_{S E P}}{d t} & =\frac{\sigma_{S E, S E P}-\sigma_{2}\left(S L_{S E P}\right)-\lambda_{X B} \sigma_{X B, S E P}(t)}{\eta}
\end{aligned}
$$


where the parameter $\lambda_{X B}$ is a scalar used to account for differences in force generation in vivo versus in vitro. (The value value $\lambda_{X B}=1.4$, determined by Tewari et al. (2016b) accounts for slightly lower force generation in vitro versus in vivo.)

The $S L$ and $\frac{d S L}{d t}$ computed from Eq. (17) are used in Eqs. (5) which govern cross-bridge dynamics in each segment. The dynamical state of the cross-bridge model in each segment, in turn, appears in Eq. (17), which governs $S L(t)$ for each segment.

The series element elastic force for each segment is computed to be proportional to the difference between the sarcomere length and the sarcomere length calculated from natural myofiber strain:

$$
\begin{aligned}
\sigma_{S E, R V} & =K_{S E}\left(S L_{0, R V}-S L_{R V}\right) \\
\sigma_{S E, L V} & =K_{S E}\left(S L_{0, L V}-S L_{L V}\right) \\
\sigma_{S E, S E P} & =K_{S E}\left(S L_{0, S E P}-S L_{S E P}\right)
\end{aligned}
$$

where

$$
\begin{aligned}
S L_{0, \#} & \left.=S L_{r e f} \exp \left(\epsilon_{f, \#}\right)\right) \\
\epsilon_{f, \#} & =\frac{1}{2} \ln \left(\frac{A_{m, \#}}{A_{m, r e f, \#}}\right)-\frac{1}{12} z_{\#}^{2}-0.019 z_{\#}^{4} \\
z_{\#} & =\frac{3 C_{m, \#} V_{W, \#}}{2 A_{m, \#}} \\
V_{m, \#} & =\frac{\pi}{6} x_{m, \#}\left(x_{m, \#}^{2}+3 y_{m}^{2}\right) \\
A_{m, \#} & =\pi\left(x_{m, \#}^{2}+y_{m}^{2}\right) \\
C_{m, \#} & =\frac{2 x_{m, \#}}{x_{m, \#}^{2}+y_{m}^{2}} .
\end{aligned}
$$

Here $A_{m, \#}$ the midwall surface area of segment \#, $A_{m, r e f, \#}$ is a reference midwall surface area, $C_{m \text {,\# }}$ is the curvature of the midwall surface, $V_{w, \#}$ is the wall volume of wall segment $\mathrm{i}, V_{m, \#}$ is the midwall volume, and $x_{m}$,\# and $y_{m}$ determine the geometry of the LV and RV cavity (see Lumens et al. (2009)). The four variables of the TriSeg heart model, $x_{m, R V}, x_{m, L V}, x_{m, S E P}$, and $y_{m}$ that determine the geometry of the ventricular cavities, are listed in Table 8.

Table 8. State variables in TriSeg (Heart) model

\begin{tabular}{llll}
\hline State Variable & Definition & Units & Variable name in code \\
\hline $\mathrm{x}_{m}, R V$ & $\begin{array}{l}\text { Maximal axial distance } \\
\text { from RV midwall surface to origin }\end{array}$ & $\mathrm{cm}$ & Xm_RV \\
$\mathrm{x}_{m}, L V$ & $\begin{array}{l}\text { Maximal axial distance } \\
\text { from LV midwall surface to origin }\end{array}$ & $\mathrm{cm}$ & $\mathrm{Xm}$.LV \\
$\mathrm{x}_{m}, S E P$ & $\begin{array}{l}\text { Maximal axial distance } \\
\text { from SEP midwall surface to origin }\end{array}$ & $\mathrm{cm}$ & Xm_SEP \\
$\mathrm{y}_{m}$ & Radius of midwall junction circle & $\mathrm{cm}$ & $\mathrm{ym}$ \\
\hline
\end{tabular}

For given wall volumes and ventricular volumes, the geometry of the heart is solved such that equilibrium of radial and axial tensile forces is achieved at the junction margin (i.e., where the three wall segments meet forming ventricular cavities).

Tension in the midwall of each segment is calculated as a function of stress:

$$
T_{m, \#}=\frac{V_{W, \#} \sigma_{S E, \#}}{2 A_{m, \#}}\left(1+\frac{z^{2}}{3}+\frac{z^{4}}{5}\right)
$$

Axial and radial components of the tension are computed 


$$
\begin{aligned}
& T_{x, \#}=T_{m, \#} \frac{2 x_{m, \#} y_{m}}{x_{m, \#}^{2}+y_{m}^{2}} \\
& T_{y, \#}=T_{m, \#} \frac{-x_{m, \#}^{2}+y_{m}^{2}}{x_{m, \#}^{2}+y_{m}^{2}}
\end{aligned}
$$

The four unknowns of the model $-x_{m, R V}, x_{m, L V}, x_{m, S E P}$, and $y_{m}$-are determined by satisfying the relations

$$
\begin{aligned}
V_{m, L V}= & -V_{L V}-\frac{1}{2} V_{w, L V}-\frac{1}{2} V_{w, S E P}+V_{m, S E P} \\
V_{m, R V}= & +V_{R V}-\frac{1}{2} V_{w, R V}-\frac{1}{2} V_{w, S E P}-V_{m, S E P} \\
& T_{x, R V}+T_{x, L V}+T_{x, S E P}=0 \\
& T_{y, R V}+T_{y, L V}+T_{y, S E P}=0 .
\end{aligned}
$$

Transmural pressures are computed

$$
P_{\text {trans,\# }}=\frac{2 T_{x, \#}}{y_{m}}
$$

\begin{tabular}{|c|c|c|c|}
\hline Parameter & Definition & Value and Units & Variable name in code \\
\hline$V_{w, L V}$ & LV wall volume & $\begin{array}{l}\text { input } \\
\text { (experimental data), } \mathrm{mL}\end{array}$ & $V w_{-} L V$ \\
\hline$V_{w, S E P}$ & Septal wall volume & & Vw_SEP \\
\hline$V_{w, R V}$ & RV wall volume & $\begin{array}{l}\text { input } \\
\text { (experimental data), } \mathrm{mL}\end{array}$ & $\mathrm{Vw}_{-} \mathrm{RV}$ \\
\hline$A_{m, r e f}^{L W}$ & $\begin{array}{l}\text { LV midwall reference } \\
\text { surface area }\end{array}$ & adjustable, $\mathrm{cm}^{2}$ & Amref_LV \\
\hline$A_{m, r e f}^{S E P}$ & $\begin{array}{l}\text { Septal midwall reference } \\
\text { surface area }\end{array}$ & adjustable, $\mathrm{cm}^{2}$ & Amref_SEP \\
\hline$A_{m, r e f}^{R W}$ & $\begin{array}{l}\text { RV midwall reference } \\
\text { surface area }\end{array}$ & adjustable, $\mathrm{cm}^{2}$ & Amref_RV \\
\hline$K_{S E}$ & Stiffness of series element & $50000 \mathrm{mmHg} / \mu \mathrm{m}$ & Kse \\
\hline$\eta$ & Viscosity coefficient of myofibers & $1 \mathrm{mmHg} \cdot \mathrm{sec} \cdot \mu \mathrm{m}^{-1}$ & eta \\
\hline
\end{tabular}

and the pressures in the cavities are computed

$$
\begin{aligned}
& P_{L V}=-P_{\text {trans }, L V} \\
& P_{R V}=+P_{\text {trans }, R V} .
\end{aligned}
$$

\subsection{Model Parameters}

Parameters defining the mass and geometry of the heart are identified from data on individual animals are defined in Table 9.

Table 9. Parameters in TriSeg (Heart) model

\section{Lumped-Parameter Cardiovascular Systems Model}

\subsection{Model Variables and Equations:}

The lumped-parameter model illustrated in Fig. 4 is used to simulate pressures and flows in the systemic and pulmonary circuits. This simple lumped model invokes eight parameters representing: pulmonary resistance $R_{p u l}$, pulmonary arterial and venous compliances $C_{P A}$ and $C_{P V}$, systemic arterials resistances $R_{A o}$ and $R_{s y s}$, systemic arterial compliance $C_{S A}$, and systemic venous compliance $C_{S V}$, systemic arterial resistance and aortic compliance $C_{A O}$. 


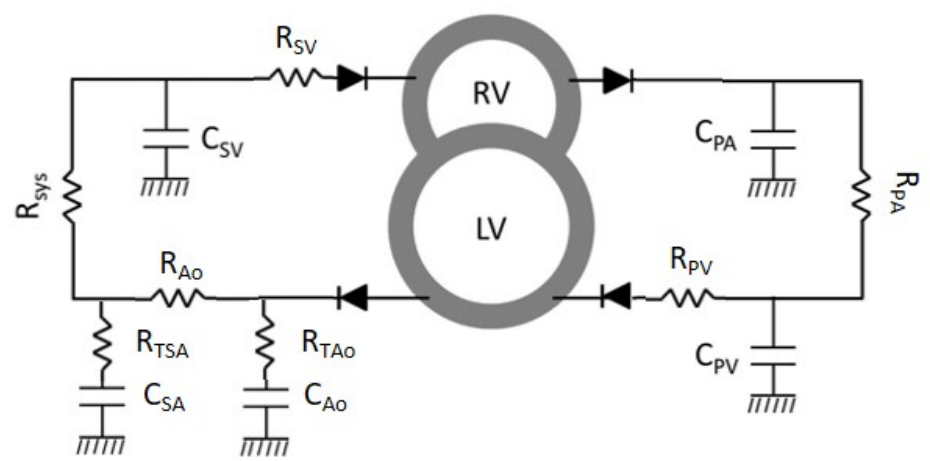

Figure 4. Cardiovascular system (CVS) diagram. Adopted from Tewari et al. Tewari et al. $(2016 \mathrm{a}, \mathrm{b}) . C_{P A}, C_{P V}, C_{S A}, C_{A o}$, and $C_{S V}$ represent lumped compliances of pulmonary arteries, pulmonary veins, systemic arteries, aorta, and systemic veins. $R_{p u l}, R_{s y s}$, and $R_{A o}$ represent vascular resistances. The lumped-parameter representations of the systemic and pulmonary circuits are coupled to the TriSeg heart model of Lumens et al. (2009), described below.

Flow through a resistive element is calculated

$$
q=\frac{P_{1}-P_{2}}{R}
$$

where $P_{1}-P_{2}$ is the pressure drop across the element, and $\mathrm{R}$ is the resistance. Pressure in a compliant/capacitive element is governed by

$$
\frac{d P}{d t}=\frac{F_{\text {in }}-F_{\text {out }}}{C}
$$

where $F_{\text {in }}-F_{\text {out }}$ is the rate of change of blood volume in the element. Table 10 lists the variables of the cardiovascular systems model. These variables and Eqs. 21 and 22 are invoked in the MATLAB code Cardiovascularmechancis.m.

\begin{tabular}{|c|c|c|c|}
\hline Parameter & Definition & Units used in code & Variable name in code \\
\hline \multicolumn{4}{|c|}{ Cardiovascular system model state variables } \\
\hline$V_{L V}$ & Left ventricle volume & $\mathrm{mL}$ & V_LV \\
\hline$V_{R V}$ & Right ventricle volume & $\mathrm{mL}$ & V_RV \\
\hline$v_{S V}$ & Volume of systemic vein & $\mathrm{mL}$ & V_SV \\
\hline$V_{P V}$ & Volume of pulmonary vein & $\mathrm{mL}$ & V_PV \\
\hline$V_{S A}$ & Volume of systemic artery & $\mathrm{mL}$ & V_SA \\
\hline$V_{P A}$ & Volume of pulmonary artery & $\mathrm{mL}$ & V_PA \\
\hline$V_{A O}$ & Volume of aorta & $\mathrm{mL}$ & V_Ao \\
\hline \multicolumn{4}{|c|}{ Pressures computed from volume state variables } \\
\hline$P_{S V}$ & Systemic venous pressure & $\mathrm{mmHg}$ & P_SV \\
\hline$P_{P V}$ & Pulmonary venous pressure & $\mathrm{mmHg}$ & P_PV \\
\hline$P_{P A}$ & Pulmonary arterial pressure & $\mathrm{mmHg}$ & P_PA \\
\hline$P_{A O}$ & Aortic pressure (proximal to TAC) & $\mathrm{mmHg}$ & P_Ao \\
\hline$P_{S A}$ & Systemic arterial pressure (distal to TAC) & $\mathrm{mmHg}$ & P_SA \\
\hline
\end{tabular}

Table 10. Variables used in lumped-parameter cardiovascular model

\subsection{Identification of Model Parameters:}

Table 11 lists the parameters used in the lumped circulatory model.

The systemic compliances $\left(C_{S A}, C_{A 0}, C_{S V}\right)$ are fixed to produce a pulse pressure of roughly 33 $\mathrm{mmHg}$ for simulations of sham control rats. The pulmonary compliance $\left(C_{P A}, C_{P V}\right)$ are fixed to roughly have the target value of $12 \mathrm{mmHg}$ for the pulmonary pulse pressure. The resistance $R_{A o}$ is arbitrarily set to have a small pressure drop of $4 \mathrm{mmHg}$ between the aorta and systemic arteries 
Table 11. Parameter used in the CVS model

\begin{tabular}{|c|c|c|c|}
\hline Parameter & Definition & Value and Units & $\begin{array}{l}\text { Variable name } \\
\text { in code }\end{array}$ \\
\hline$C_{A 0}$ & Proximal aortic compliance & $0.0022045 \mathrm{~mL} \cdot \mathrm{mmHg}^{-1}$ & C_Ao \\
\hline$C_{S A}$ & Systemic arterial compliance & $0.0077157 \mathrm{~mL} \cdot \mathrm{mmHg}^{-1}$ & C_SA \\
\hline$c_{S V}$ & Systemic venous compliance & $2.5 \mathrm{~mL} \cdot \mathrm{mmHg}^{-1}$ & C_SV \\
\hline$C_{P A}$ & Pulmonary arterial compliance & $0.013778 \mathrm{~mL} \cdot \mathrm{mmHg}^{-1}$ & C_PA \\
\hline$C_{P V}$ & Pulmonary venous compliance & $0.25 \mathrm{~mL} \cdot \mathrm{mmHg}^{-1}$ & $C_{-}^{-} \mathrm{PV}$ \\
\hline$R_{A O}$ & Proximal aortic resistance & $2.5 \mathrm{mmHg} \cdot \mathrm{sec} \cdot \mathrm{mL}^{-1}$ & R_Ao \\
\hline$R_{\text {sys }}$ & Systemic vasculature resistance & adjustable, $\mathrm{mmHg} \cdot \mathrm{sec} \cdot \mathrm{mL}^{-1}$ & R_sys \\
\hline$R_{S V}$ & Systemic veins resistance & $0.25 \mathrm{mmHg} \cdot \mathrm{sec} \cdot \mathrm{mL}^{-1}$ & R_SV \\
\hline$R_{T A O}$ & Transmural aortic resistance & $0.5 \mathrm{mmHg} \cdot \mathrm{sec} \cdot \mathrm{mL}^{-1}$ & R_tAo \\
\hline$R_{T S A}$ & Transmural systemic artery resistance & $4 \mathrm{mmHg} \cdot \mathrm{sec} \cdot \mathrm{mL}^{-1}$ & R_tSA \\
\hline$R_{P A}$ & Pulmonary vasculature resistance & $7.58 \mathrm{mmHg} \cdot \mathrm{sec} \cdot \mathrm{mL}^{-1}$ & R_PA \\
\hline$R_{P V}$ & Pulmonary veins resistance & $0.25 \mathrm{mmHg} \cdot \mathrm{sec} \cdot \mathrm{mL}^{-1}$ & R_PV \\
\hline$R_{V L V}$ & Valve resistance & $0.05 \mathrm{mmHg} \cdot \mathrm{sec} \cdot \mathrm{mL}^{-1}$ & R_VLV \\
\hline$R_{T A C}$ & Resistance of TAC & adjustable, $\mathrm{mmHg} \cdot \mathrm{sec} \cdot \mathrm{mL}^{-1}$ & R_TAC \\
\hline
\end{tabular}

for cardiac output of the mean value of $95 \mathrm{~mL}$ per min. The systemic venous resistance $R_{S V}$ is set so that the mean pressure in the systemic veins for sham control rats is $3 \mathrm{mmHg}$. The pulmonary resistances $R_{P A}$ and $R_{P V}$ are set to give a mean pulmonary arterial pressure of $21 \mathrm{mmHg}$ and pulmonary venous pressure of $9 \mathrm{mmHg}$ in the sham control rats.

The two parameters in the circulation model that are adjusted to match measured data on individual TAC and sham rats are $R_{T A C}$ and $R_{\text {sys }}$. The resistance $R_{T A C}$ represents the resistance across the transverse aortic constriction (TAC), and is set to zero in sham-operated rats. In TAC rats, the value of this resistance is obtained based on the pressure gradient across the TAC constriction estimated from ultrasound measurements of the velocity gradient. The pressure drop across the constriction is computed $\Delta P_{T A C}=\frac{1}{2} \rho\left(V_{2}^{2}-V_{1}^{2}\right)$, where $V_{1}$ and $V_{2}$ are the velocities on either side of the TAC constriction. Given an estimated pressure drop the resistance is computed $R_{T A C}=\frac{\Delta P_{T A C}}{C O}$, where CO is the cardiac output. The systemic resistance $R_{s y s}$ is adjusted so that the mean arterial pressure (MAP) is maintained at $93.3 \mathrm{mmHg}$. (Model fitting procedures are detailed below in Section 6.)

\section{Model fits and predictions associated with individual rats}

\subsection{Summary:}

The cardiac energy metabolism and the whole-body cardiovascular mechanics model (which includes the heart model) are implemented as separate modules. These models are matched to data on an individual animal basis. The cardiac energetics model takes as an input the myocardial ATP consumption rate, the measured metabolite pools levels, and the measured mitochondrial ATP synthesis capacity, and outputs the cytoplasm concentrations of phosphate metabolites. The cardiac mechanics code takes as an input the cytoplasmic concentrations of phosphate metabolites (namely, ATP, ADP, and Pi) and computes as an output the ventricular end-systolic and end-diastolic volumes and arterial pressures to compare to measured data, and the myocardial ATP hydrolysis rate to use in the energetics module. The energetics and mechanics models are iteratively run until they simultaneously converge to a steady state at fit the target cardiovascular data.

\subsection{Relationship between cross-bridge cycle and ATP hydrolysis rates:}

The relationship between cross-bridge cycle rate and J_ATP, the rate myocardial oxygen consumption rate, is based on matching the myocardial oxygen consumption rate predicted by the model to that observed for the working rat heart. Duvelleroy et al. (1976) report a mean oxygen consumption rate of approximately $M V O 2=0.31 \mathrm{~mL} \cdot(\mathrm{min} \cdot \mathrm{g})^{-1}$ for work rates corresponding 
Table 12. Input arguments and adjustable parameters for cardiovascular mechanics model

\begin{tabular}{|c|c|c|c|c|}
\hline Parameter & $\begin{array}{l}\text { Variable } \\
\text { name in } \\
\text { code }\end{array}$ & Definition & $\begin{array}{l}\text { Units used in } \\
\text { code }\end{array}$ & Values \\
\hline $\mathrm{HR}$ & $\mathrm{HR}$ & Heart rate & bpm & $\begin{array}{l}318.6-367 \text { for sham } 294- \\
349 \text { for TAC. Set to mea- }\end{array}$ \\
\hline Vw,LV & Vw_LV & LV wall volume & $\mathrm{mL}$ & $\begin{array}{l}\text { sured value } \\
0.564-0.853 \text { for sham } \\
0.863-1.22 \text { for TAC. Set } \\
\text { as } 2 / 3 \text { of measured LV } \\
\text { volume }\end{array}$ \\
\hline Vw,SEP & Vw_SEP & Septal wall volume & $\mathrm{mL}$ & $\begin{array}{l}0.2821-0.4266 \text { for sham } \\
0.431-0.61 \text { for TAC. Set } \\
\text { as } 1 / 3 \text { of measured LV vol- } \\
\text { ume }\end{array}$ \\
\hline Vw,RV & Vw_RV & RV wall volume & $\mathrm{mL}$ & $\begin{array}{l}0.282-0.373 \text { for sham } \\
0.249-0.605 \text { for TAC. Set } \\
\text { as measured RV free wall } \\
\text { volume }\end{array}$ \\
\hline$A_{m, r e f}^{L W}$ & Amref_LV & $\begin{array}{l}\text { LV midwall reference } \\
\text { surface area }\end{array}$ & $\mathrm{cm}^{2}$ & $\begin{array}{l}1.6865-2.465 \text { for SHAM } \\
2.299-2.966 \text { for TAC. Ad- } \\
\text { justed to fit data }\end{array}$ \\
\hline$A_{m, r e f}^{S E P}$ & Amref_SEP & $\begin{array}{l}\text { Septal midwall refer- } \\
\text { ence surface area }\end{array}$ & $\mathrm{cm}^{2}$ & $\begin{array}{l}1.055-1.487 \text { for sham } \\
1.299-1.620 \text { for TAC. } \\
\text { Adjusted to fit data }\end{array}$ \\
\hline$A_{m, r e f}^{R W}$ & Amref_RV & $\begin{array}{l}\text { RV midwall reference } \\
\text { surface area }\end{array}$ & $\mathrm{cm}^{2}$ & $\begin{array}{l}2.629-3.612 \text { for sham } \\
3.135-5.538 \text { for TAC. } \\
\text { Adjusted to fit data }\end{array}$ \\
\hline$k_{\text {force }}$ & $\mathrm{k}_{-}$force & $\begin{array}{l}\text { Model parameter for } \\
\text { force dependent su- } \\
\text { per relax transition }\end{array}$ & $\mathrm{N}^{-1} \mathrm{~m}^{2}$ & $\begin{array}{l}(0.905-3.312) \times 10^{-3} \text { for } \\
\text { sham }(1.464-3.783) \times 10^{-3} \\
\text { for TAC. Adjusted to fit } \\
\text { data }\end{array}$ \\
\hline$k_{S R}$ & $\mathrm{ksr}$ & $\begin{array}{l}\text { On rate constant for } \\
\text { super relax state }\end{array}$ & $s^{-1}$ & $\begin{array}{l}9.021-33.013 \text { for sham } \\
14.598-37.708 \text { for TAC. } \\
\text { Adjusted to fit data }\end{array}$ \\
\hline$R_{\text {sys }}$ & R_sys & $\begin{array}{l}\text { Systemic vasculature } \\
\text { resistance }\end{array}$ & $\begin{array}{l}\mathrm{mmHg} \cdot \mathrm{sec} . \\
\mathrm{mL}^{-1}\end{array}$ & $\begin{array}{l}38.071-71.886 \text { for sham } \\
50.577-125.33 \text { for TAC. } \\
\text { Adjusted to fit data }\end{array}$ \\
\hline$R_{T A C}$ & R_TAC & resistance of TAC & $\begin{array}{l}\mathrm{mmHg} \cdot \mathrm{sec} . \\
\mathrm{mL}^{-1}\end{array}$ & $\begin{array}{l}0 \text { for sham } 7.11-22.25 \text { for } \\
\text { TAC. Adjusted to fit data }\end{array}$ \\
\hline $\begin{array}{l}\text { MgATP_cyto- } \\
\text { plasm }\end{array}$ & MgATP & cytosolic [MgATP] & 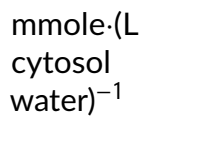 & $\begin{array}{l}7.214-9.439 \text { for sham } \\
4.938-9.063 \text { for TAC } \\
\text { Predicted from energetics } \\
\text { model }\end{array}$ \\
\hline $\begin{array}{l}\text { MgADP_cyto- } \\
\text { plasm }\end{array}$ & MgADP & cytosolic [MgADP] & 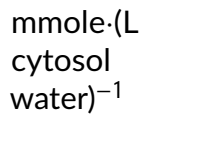 & $\begin{array}{l}0.047-0.06 \text { for sham } \\
0.027-0.055 \text { for TAC. } \\
\text { Predicted from energetics } \\
\text { model }\end{array}$ \\
\hline $\begin{array}{l}\text { Pi_cyto- } \\
\text { plasm }\end{array}$ & $\mathrm{Pi}$ & cytosolic total [Pi] & 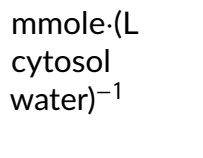 & $\begin{array}{l}0.740-2.197 \text { for sham } \\
1.922-2.798 \text { for TAC. } \\
\text { Predicted from energetics } \\
\text { model }\end{array}$ \\
\hline
\end{tabular}

to resting state in blood perfused working hearts. Using a myocardial cell density (in terms of cardiomyocyte volume per unit mass of myocardium) of $\rho_{\text {cell }}=0.694 \mathrm{~mL} \cdot \mathrm{g}^{-1}$ and assuming a $\mathrm{P} / \mathrm{O} 2$ ratio (moles of ATP synthesized per mole of $\mathrm{O} 2$ consumed) of $4.5 \mathrm{Wu}$ et al. (2008), we estimate a resting ATP hydrolysis rate of $1.30 \mathrm{mmol} \cdot\left(\mathrm{sec} \cdot \mathrm{L}\right.$ cell) ${ }^{-1}$. (This value is approximately 2.5 times higher than the estimated resting ATP hydrolysis rate of to $0.547 \mathrm{mmol} \cdot(\mathrm{sec} \cdot \mathrm{L} \mathrm{cell})^{-1}$ for 
human myocardium Gao et al. (2019).)

Simulations of the cardiovascular mechanics model predict an average cross-bridge cycling rate of $5.03 \mathrm{sec}^{-1}$ for the mean sham-operated control rat. Assuming a fixed proportionality between cross-bridge cycling rate and myocardial ATP hydrolysis rate, yields a constant of proportionality of

$$
\begin{aligned}
& \text { ATP hydrolysis rate }\left(\mathrm{mmol} \cdot(\mathrm{sec} \cdot \mathrm{L} \text { cell })^{-1}\right)= \\
& 0.258\left(\mathrm{mmol} \cdot(\mathrm{L} \text { cell })^{-1}\right) \times \text { crossbridge cycling rate }\left(\mathrm{sec}^{-1}\right) .
\end{aligned}
$$

If we assume that roughly $3 / 4$ of the ATP consumed by the cardiomyocyte is consumed by the myosin ATPase, we estimate from this constant of proportionality the density of cross-bridgeforming units in a cardiomyocyte to be roughly $0.34 \mathrm{mmol}$ per liter of cell. This density has been independently estimated to be $0.25 \mathrm{mmol}$ per liter of cell for skeletal myocytes (Barclay et al. (2010)).

\subsection{Fitting data on individual rats:}

The full set of adjustable parameters invoked in the cardiovascular systems model is listed in Table 12. Certain adjustable parameters are set based on direct measurements and others are adjusted so that simulation outputs match measured data. Seven parameter values $-A_{m, r e f}^{L W "}, A_{m, r e f}^{S E P}, A_{m, r e f}^{R W}$ , $k_{\text {force }}, k_{S R}, R_{s y s}, R_{T A C}-$ are adjusted to fit model predictions to data from individual animals on end-systolic and end-diastolic volumes and estimated pressure drop across the aortic constriction in TAC animals, and to simultaneously maintain a fixed mean arterial pressure of $93.3 \mathrm{mmHg}$, to maintain end-diastolic sarcomere lengths in the LV, septum, and RV of $2.2 \mu \mathrm{m}$.

Ranges of estimated values of are listed in Table 12. Values of anatomical/geometric parameters representing heart masses and reference areas are higher in TAC rats than in sham control rats, reflecting hypertrophic remodeling. The parameters $k_{\text {force }}$ and $k_{S R}$ govern the transition out of the inaccessible super-relaxed state in the calcium-activation model. Increased in the values of these parameters represent increased levels of phosphorylation of myosin binding protein C. Thus, the higher values of these parameters in TAC compared to sham animals represent a prediction that phosphorylation of this protein is increased in the TAC animals.

Simulations of TAC rats consistently show lower ATP, ADP, and $\mathrm{CrP}$, reflecting reductions in the total adenine nucleotide and creatine pools. (See below.) Lower ADP levels require a compensatory increase in inorganic phosphate to maintain ATP synthesis.

The ranges of values of cross-bridge cycle rate, ATP hydrolysis rate, and end-systolic and enddiastolic volumes are listed in Table 13.

\begin{tabular}{|c|c|c|c|}
\hline Variable & Definition & Units used in code & Values \\
\hline $\begin{array}{l}\text { rate_of_XB_turn- } \\
\text { over_ave }\end{array}$ & $\begin{array}{l}\text { Cross bridge cycling } \\
\text { rate }\end{array}$ & $\sec ^{-1}$ & $\begin{array}{l}\text { 3.5874-5.3658 for sham } \\
2.606-5.4381 \text { for TAC }\end{array}$ \\
\hline x_ATPase & ATP hydrolysis rate & $\mathrm{mmol} \cdot(\mathrm{sec} \cdot \mathrm{L} \cdot \mathrm{cell})^{-1}$ & $\begin{array}{l}0.9301-1.392 \text { for sham } \\
0.6758-1.410 \text { for TAC }\end{array}$ \\
\hline EDLV & $\begin{array}{l}\text { End diastolic left ven- } \\
\text { tricular volume }\end{array}$ & $\mathrm{mL}$ & $\begin{array}{l}0.303-0.547 \text { for sham } \\
0.407-0.650 \text { for TAC }\end{array}$ \\
\hline ESLV & $\begin{array}{l}\text { End systolic left ven- } \\
\text { tricular volume }\end{array}$ & $\mathrm{mL}$ & $\begin{array}{l}0.093-0.232 \text { for sham } \\
0.138-0.423 \text { for TAC }\end{array}$ \\
\hline MAP & Mean arterial pressure & $\mathrm{mmHg}$ & $\begin{array}{l}93.3 \text { for both TAC and } \\
\text { sham }\end{array}$ \\
\hline
\end{tabular}

Table 13. Output arguments for cardiovascular mechanic model

The set of input parameters invoked in the cardiovascular systems model is listed in Table 3. The input parameters TAN, CRtot, and Ox_capacity are all measured for each individual rat. The ATP hydrolysis rate $\left(x_{\text {ATPase }}\right)$ is predicted by the mechanics model (see above). The relationships between metabolite pools from Gao et al. (2019) are used to estimate the total exchangeable 
phosphate (TEP):

$$
\mathrm{TEP}=P_{0}-p\left(\left(A_{0}-\mathrm{TAN}\right) / a\right)
$$

where, $P_{0}=35.446 \mathrm{mmol} \cdot(\mathrm{L} \text { cell })^{-1}, A_{0}=10.26 \mathrm{mmol} \cdot(\mathrm{L} \text { cell })^{-1}$, are reference TEP and TAN values, $p=0.283 \mathrm{mmol} \cdot\left(\mathrm{L}\right.$ cell.year) ${ }^{-1}$ and $a=0.082 \mathrm{mmol} \cdot\left(\mathrm{L}\right.$ cell.year) ${ }^{-1}$ are the slopes of the relationships between mean TEP and mean TAN and age in humans, respectively.

Output arguments from the energetics model, including the metabolite levels used in the mechanics model, are listed in Table 4.

\subsection{Predictions associated with changing metabolic/energetic parameterization:}

The predictions illustrated in Fig. 9 of Lopez et al. (2020) are made by replacing the parameters representing the metabolic state of sham control rats with those representing TAC rats and by replacing the parameters representing the metabolic state of TAC rats with those representing sham control rats.

For predictions of how mechanical function in sham rats changes when the metabolic profile is replaced with that of the average TAC rat (Fig. 9A - 9B Lopez et al. (2020)), the input metabolic parameters are set to:

$$
\begin{aligned}
\text { TAN } & =0.006976 \mathrm{M} \\
\text { CRtot } & =0.02303 \mathrm{M} \\
\text { TEP } & =0.02411 \mathrm{M} \\
\text { Ox_capacity } & =0.7482 \text { (unitless) }
\end{aligned}
$$

Note that the above average TAC rat metabolite profile are based on $n=10$ TAC rats. (TAC \#7 is excluded for reasons described in Lopez et al. (2020).)

Given these values specifying the metabolic model, the blood volume, $k_{f o r c e}$, and $k_{S R}$ are increased so that the model-predicted mean arterial pressure was $93.3 \mathrm{mmHg}$. In other words, it is assumed that baseline cardiac output and system pressure are maintained at the original physiological levels via compensatory increases in preload and myosin binding protein $C$ phosphorylation. To obtain the model predictions in Lopez et al. first the $k_{\text {force }}$ and $k_{S R}$ are proportionately increased to compensate for the metabolic dysfunction. If it is not possible to restore mean arterial pressure to the physiological level with that change alone, blood volume is increased until the mean pressure of $93.3 \mathrm{mmHg}$ is reached.

For predictions of how mechanical function in TAC rats changes when the metabolic profile is replaced with that of the average sham rat (Fig. 9C - 9D), the input metabolic parameters are set to:

$$
\begin{aligned}
\text { TAN } & =0.007624 \mathrm{M} \\
\text { CRtot } & =0.03027 \mathrm{M} \\
\text { TEP } & =0.02635 \mathrm{M} \\
\text { Ox_capacity } & =1 \text { (unitless) }
\end{aligned}
$$

Given these values specifying the metabolic model, the blood volume, $k_{f o r c e}$, and $k_{S R}$, and $R_{s y s}$ are adjusted so that the model-predicted mean arterial pressure is $93.3 \mathrm{mmHg}$ and the predicted end-diastolic volume with mean sham metabolic parameters is equal to that of the original TAC rat. In other words, it was assumed that baseline system pressure and diastolic filling level are maintained at the original physiological levels via compensatory reduction in preload, myosin binding protein $\mathrm{C}$ phosphorylation, and systemic resistance. 


\section{Running the model}

\subsection{Summary of codes}

The simulation package consists of 5 MATLAB files:

1. CardiovascualarMechanics.m

2. dXdT_CardiovascularMechanics.m

3. EnergeticsModelScript.m

4. dXdT_energetics.m

5. TrisegEquations.m

Values of all adjustable parameters are stored in spreadsheet files "Adjustable_paramaters_table_rest.xlsx" for the baseline simulations and "Adjustable_parameters_table_SWAP.xlsx" for simulations with replaced metabolic parameters.

The CardiovascularMechanics.m function is the main driver to run the mechanics model for a given animal. For instance, assigning the variable "rat_number" to 1 will execute simulations for SHAM rat number 1 . Executing the script will load the parameters associated with this animal, run the cardiovascular systems model for 120 heart beats to attain a periodic steady state, and then plot the predicted left ventricular pressure, aortic pressure, and arterial pressure along with the left-ventricular pressure volume loop for this individual animal. The target end-diastolic and end-systolic volumes and the pres-sure drop across the TAC will be indicated by dashed lines in the figures. The model will compute the predicted cross-bridge cycling rate in the LV free wall and the associated ATP hydrolysis rate.

The energetics model for a given animal is called within the cardiovascular model. Executing this script will read the metabolic/energetic parameters associated with this animal and run the model to calculate the cytosolic metabolite levels. Note the ATPase hydrolysis rate for steady state is pre-identified and is listed in column 9 of the input adjustable_parameters_table_rest.xlsx.

The numbering for rats in the input "data1.xIsx" file is as follows: the first 8 rats are SHAM rats and rat number 9 is the mean sham rat; rat number 10 to 19 are the TAC rats (TAC rat\# 7 is excluded). Therefore the first TAC rat is rat number 10 in the simulations. For example, to simulate the model for TAC rat \#1 we need assign number 10 to the variable "rat_numbers $=10$ " in the CardiovascularMehanics.m and run the code.

The model will generate output shown below in Fig. 5.
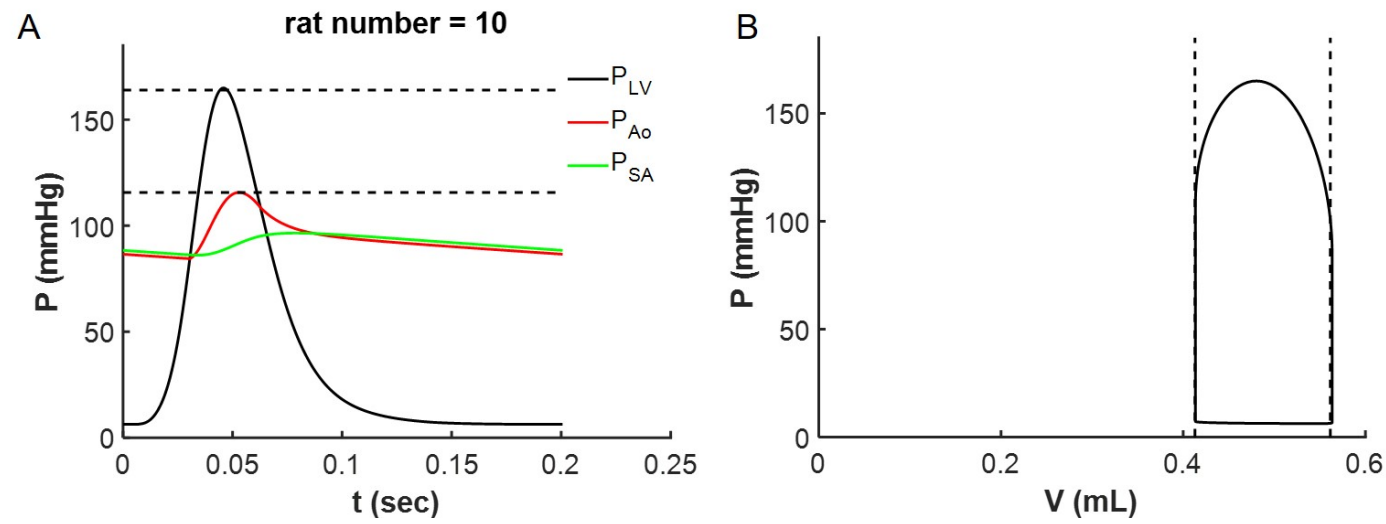

Figure 5. Model output for TAC rat \#1.

In addition to the plots illustrated above, the running the model for this individual animal results in a predicted ATP hydrolysis rate of $0.675 \mathrm{mmole} \cdot \mathrm{sec}^{-1}$. $\left(\mathrm{L} \mathrm{cell}^{-1}\right.$. Note that the input ATP hydrolysis rate is the input parameters for the energetic model for this animal (column 9, rat number 10) of the adjustable variables in the input file "adjustable_parameters_table_rest.xlsx") is equal to this 
value. Also note that the predicted values for MgATP_cytoplasm, MgADP_cytoplasm, and Pi_cyto from the energetics model are equal to the associated input parameters for the mechanics model for this animal.

\subsection{Reproduction of simulations highlighted in original paper}

The procedure detailed above may be followed to reproduce the model fits to data for any of the individual TAC or sham rats analyzed in the original paper. For example, Fig. 7 of the original paper shows model fits to sham rat \#3 and TAC rat \#2. To simulate the model for sham rat \#3 the user assigns the number 3 to the variable "rat_numbers $=3$ " in the CardiovascularMehanics. $m$ and runs the code. The resulting model output is equivalent to that presented in Fig. 7 panels $A$ and $B$ of the original paper.

To simulate the model for TAC rat \#2 the user assigns the number 11 to the variable "rat_numbers $=11$ " in the CardiovascularMehanics.m and runs the code. The resulting model output is equivalent to that presented in Fig. 7 panels $C$ and $D$ of the original paper.

Fig. 9 of the original paper illustrates the predicted effects of replacing the metabolic profile of sham rat with that of at TAC rat, and the predicted effects of replacing the metabolic profile of a TAC rat with that of a sham rat. The solid lines in Fig. 9 of the original paper represent the resting-state simulations from Fig. 7 of the paper. The dashed lines correspond to simulations associated with the metabolite swaps.

To simulate the model for sham rat \#3 with TAC metabolism settings the user assigns the number 3 to the variable "rat_numbers $=3$ " in the CardiovascularMehanics. $m$ and also assigns the number 1 to the variable "flag_swap_metabolite $=1$ " and runs the code. The resulting model output is equivalent to that presented in Fig. 9 panels $A$ and $B$ of the original paper. To simulate the model for TAC rat \#2 with sham metabolism settings the user assigns the number 11 to the variable "rat_numbers $=11$ " in the CardiovascularMehanics.m and also assigns the number 1 to the variable "flag_swap_metabolite $=1$ " and runs the code. The resulting model output is equivalent to that presented in Fig. 9 panels $C$ and $D$ of the original paper.

\section{Glossary of model codes}

EnergeticsModelScript.m: This function is used to compute the cellular energetics concentration variables for the myocardium, given input values of mitochondrial oxidative capacity, TAN, TEP, and CRtot metabolite pool values, and the rate of cellular ATP hydrolysis. The function computes the steady state of the cellular energetics model by simulating the model governed by the differential equations in $d X d T_{-}$energetics.m.

dXdT_energetics.m: This function is an implementation of the Bazil et al. (2016) model of rat myocardial mitochondrial oxidative phosphorylation. The model has 29 state variables, listed in Table 1.

Cardiovascularmechanics.m: This function simulates the pressure and flows in the whole-body cardio-vascular systems model of 1 , governed by the five-compartment lumped-parameter cardiovascular systems model coupled to the Lumens et al. TriSeg heart model. The inputs to the model include the cytosolic metabolite concentrations predicted by EnergeticsModelScript.m. The outputs of the model are the myocardial ATP hydrolysis rate (used as an input for the energetics model) and the cardiovascular variables, EDLV, ESLV, MAP, rate of ATP cellular hydrolysis, to be compared to measurements for individual rats.

dXdT_cardiovascular_mechanics.m: This function is an implantation of the whole organ cardiovasucalar mechanics model. The model has 47 state variables listed in Tables 5, 8, and 10.

TriSeg.m: This function runs the TriSeg model equations to obtain estimates for initial value for ODE solver and the associated algebraic equations. 


\section{References}

C. J. Barclay, R. C. Woodledge, and N. A. Curtin. Inferring crossbridge properties from skeletal muscle energetics. Progress in biophysics and molecular biology, 102(1):53-71, 2010. doi: 10.1016/j.pbiomolbio.2009.10.003.

J. N. Bazil, D. A. Beard, and K. C. Vinnakota. Catalytic coupling of oxidative phosphorylation, atp demand, and reactive oxygen species generation. Biophys J, 110(4):962-971, 2016. doi: 10.1016/j.bpj.2015.09.036.

K. S. Campbell, P. M. L. Janssen, and S. G. Campbell. Force-dependent recruitment from the myosin off state contributes to length-dependent activation. Biophys J, 115(3):543-553, 2018. doi: 10.1016/j.bpj.2018.07.006.

M. A. Duvelleroy, M. Duruble, J. L. Martin, B. Teisseire, J. Droulez, and M. Cain. Blood-perfused working isolated rat heart. Journal of Applied Physiology, 41(4):603-607, 1976. doi: 10.1152/ jappl.1976.41.4.603.

X. Gao, D. G. Jakovljevic, and D. A. Beard. Cardiac metabolic limitations contribute to diminished performance of the heart in aging. Biophys J, 117(12):2295-2302, 2019. doi: 10.1016/j.bpj. 2019.06.026.

P. Janssen, L. B. Stull, and E. Marbán. Myofilament properties comprise the rate-limiting step for cardiac relaxation at body temperature in the rat. Am J Physiol Heart Circ Physiol, 282(2): H499-H507, 2002. doi: 10.1152/ajpheart.00595.2001.

R. Lopez, B. Marzban, X. Gao, E. Lauinger, F. Van den Bergh, S. E. Whitesall, K. Converso-Baran, C. F. Burant, D. E. Michele, and D. A. Beard. Impaired Myocardial Energetics Causes Mechanical Dysfunction in Decompensated Failing Hearts. Function, 09 2020. ISSN 2633-8823. doi: 10.1093/function/zqaa018. URL https://doi .org/10.1093/function/zqaa018.

J. Lumens, T. Delhaas, B. Kirn, and T. Arts. Three-wall segment (triseg) model describing mechanics and hemodynamics of ventricular interaction. Ann Biomed Eng, 37(11):2234-2255, 2009. doi: 10.1007/s10439-009-9774-2.

J. J. Rice, F. Wang, D. M. Bers, and P. P. De Tombe. Approximate model of cooperative activation and crossbridge cycling in cardiac muscle using ordinary differential equations. Biophysical Journal, 95(5):2368-2390, 2008. ISSN 15420086. doi: 10.1529/biophysj.107.119487. URL http://dx.doi.org/10.1529/biophysj.107.119487.

S. G. Tewari, B. S. M., B. M. Palmer, and D. A. Beard. Dynamics of cross-bridge cycling, atp hydrolysis, force generation, and deformation in cardiac muscle. J Mol Cell Cardiol, 96:11-25, 2016a. doi: 10.1016/j.yjmcc.2015.02.006.

S. G. Tewari, B. S. M., K. C. Vinnakota, J. M. Rice, P. M. Janssen, and D. A. Beard. Influence of metabolic dysfunction on cardiac mechanics in decompensated hypertrophy and heart failure. J Mol Cell Cardiol, 94:162-175, 2016b. doi: 10.1016/j.yjmcc.2016.04.003.

K. C. Vinnakota, F. Wu, M. J. Kushmerick, and D. A. Beard. Multiple ion binding equilibria, reaction kinetics, and thermodynamics in dynamic models of biochemical pathways. Methods Enzymol, 454:29-68, 2009. doi: 10.1016/S0076-6879(08)03802-0.

F. Wu, E. Y. Zhang, J. Zhang, R. J. Bache, and D. A. Beard. Phosphate metabolite concentrations and ATP hydrolysis potential in normal and ischaemic hearts. Journal of Physiology, 586(17): 4193-4208, 2008. ISSN 00223751. doi: 10.1113/jphysiol.2008.154732. 
Reproducibility report for: Computational Modeling of Coupled Energetics and Mechanics in the Rat Ventricular Myocardium.

Submitted to: Physiome

Manuscript number/identifier: S000007

Curation outcome summary: Successfully reproduced Figure 7 and Figure 9 of the original paper and Figure 5 of the Physiome manuscript.

Box 1: Criteria for repeatability and reproducibility

$\square$ Model source code provided:

Source code: a standard procedural language is used (e.g. MATLAB, Python, C)

$\square$ There are details/documentation on how the source code was compiled

$\square$ There are details on how to run the code in the provided documentation

The initial conditions are provided for each of the simulations

Details for creating reported graphical results from the simulation results

$\square$ Source code: a declarative language is used (e.g. SBML, CelIML, NeuroML)

$\square$ The algorithms used are defined or cited in previous articles

$\square$ The algorithm parameters are defined

$\square$ Post-processing of the results are described in sufficient detail

\section{Executable model provided:}

The model is executable without source (e.g. desktop application, compiled code, online service)

$\square$ There are sufficient details to repeat the required simulation experiments

\section{The model is described mathematically in the article(s):}

$\square$ Equations representing the biological system

There are tables or lists of parameter values

There are tables or lists of initial conditions

$\square$ Machine-readable tables of parameter values

$\square$ Machine-readable tables of initial conditions

$\square$ The simulation experiments using the model are described mathematically in the article:

$\square$ Integration algorithms used are defined

$\square$ Stochastic algorithms used are defined

$\square$ Random number generator algorithms used are defined

$\square$ Parameter fitting algorithms are defined

The paper indicates how the algorithms yield the desired output 
Box 2: Criteria for accessibility

Model/source code is available at a public repository or researcher's web site

$\square$ Prohibitive license provided

$\square$ Permissive license provided

$\square$ Open-source license provided

All initial conditions and parameters are provided

$\square$ All simulation experiments are fully defined (events listed, collection times and measurements specified, algorithms provided, simulator specified, etc.)

Box 3: Rules for Credible practice of Modeling and Simulation ${ }^{a}$

aModel credibility is assessed using the Interagency Modeling and Ananlysis Group conformance rubric: https://www.imagwiki.nibib.nih.gov/content/10-simple-rules-conformance-rubric

Define context clearly: Extensive

Use appropriate data: Extensive

Evaluate within context: Extensive

List limitations explicitly: Insufficient

Use version control: Adequate

Document adequately: Extensive

Conform to standards: Insufficient

Box 4: Evaluation

Model and its simulations could be repeated using provided declarative or procedural code

Model and its simulations could be reproduced 
Summary comments: Details of the model are provided in the Supplemental Materials and codes were made available via a Github link provided (https://github.com/beards-lab/Rat-Cardiac-Energetic). These were used in our attempt to reproduce the results presented in the manuscript. We were able to successfully reproduce Figure 7 and Figure 9 of the original paper and Figure 5 of the Physiome manuscript, after following the instructions described in this paper.

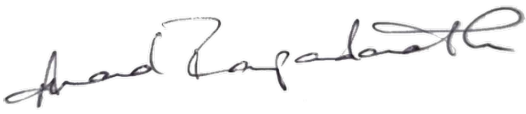

Anand K. Rampadarath ${ }^{1}$, PhD Curator

Center for Reproducible Biomedical Modeling

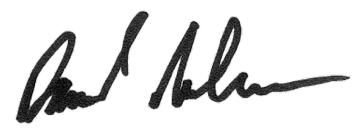

David P. Nickerson, PhD Curation Service Director

Center for Reproducible Biomedical Modeling

Auckland Bioengineering Institute, University of Auckland

\footnotetext{
1Email: a.rampadarath@auckland.ac.nz
} 